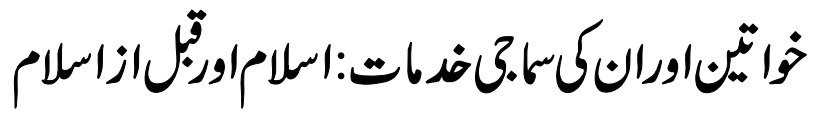

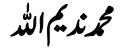 \\ مُر فيصل فياء

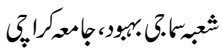 \\ اور

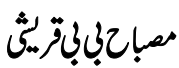

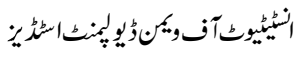 \\ بامدندهباثشورو
}

\section{تلخيص مقاله}

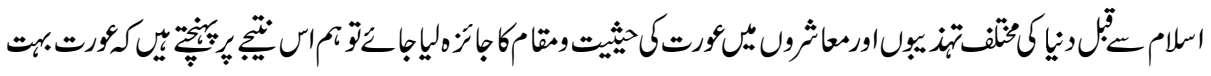

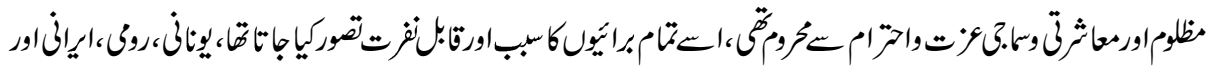

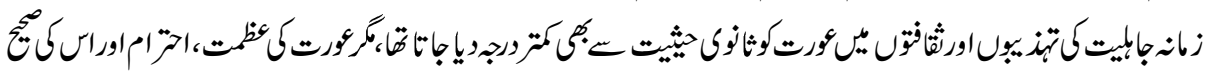

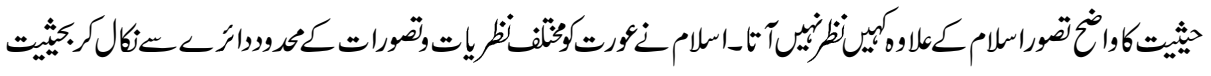

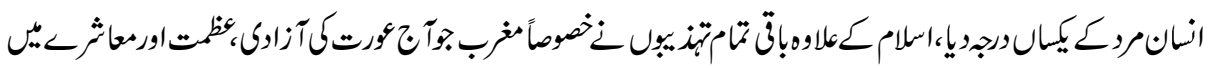

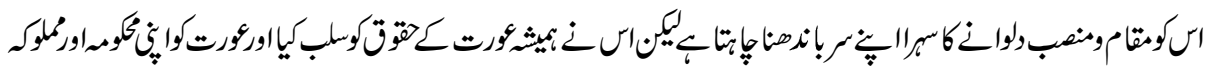

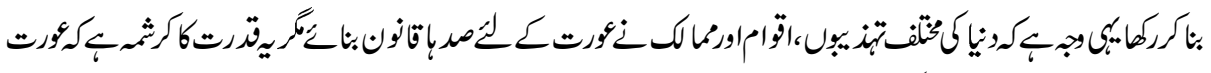

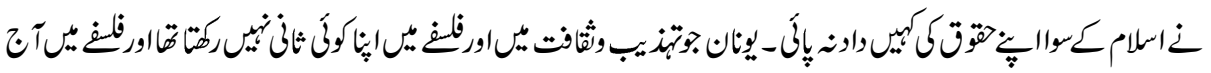

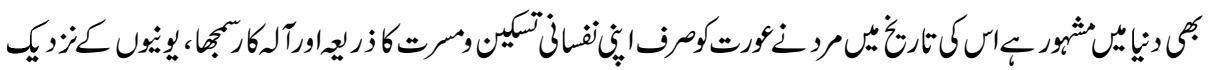

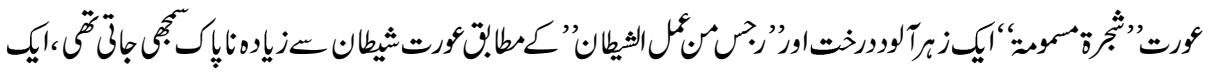

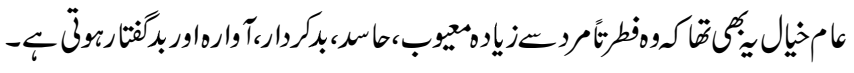

\begin{abstract}
The vast study and perusal of the social status and social contribution of women to a prosperous society reveals that before the emergence of Islam the status of women in society was just a scratch. They were behaved as if they were some sort of chattel. The birth of a daughter was condemned and the father of a daughter felt himself contemptible. The Romans believed that a woman is a shape of God's wrath. Till the end of sixteenth century The French did not believe that a woman, like a man, bears soul in the body. The Arabs used to bury their newly born daughter and they believed that the birth of a daughter is an indication that our gods are angry with us. The researcher concluded that the woman was not considered
\end{abstract}


even a human being. The Hindus used to burn or bury living wife with her deceased husband and they did not allow a widow to live in the society. The all ancient civilizations were indulged in this abominable act. On the emergence of Islam the woman, first time in human history, got her natural rights and social status. They started participation in social work as teachers, nurses and even started getting knowledge with equal opportunity as compared to men were privileged in the society. The contribution of women in the society was empowered by new Islamic vision. We find that their contribution, even in the battle-fields was marvelous and exuberant. The social status of a woman bestowed them to pay their duties independently as well as to demand their legal rights. The Islamic society founded by the Holly Prophet (s.a.w) gave freedom to women in the society.

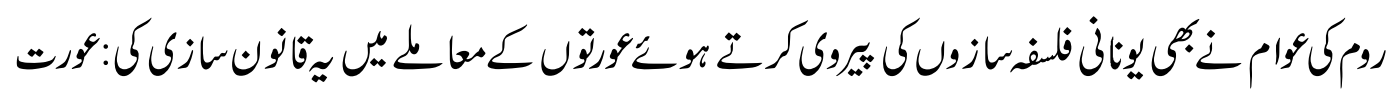

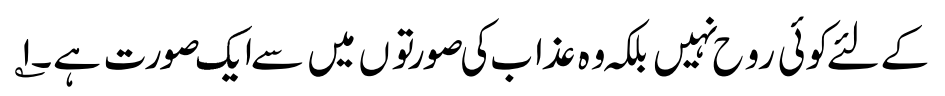

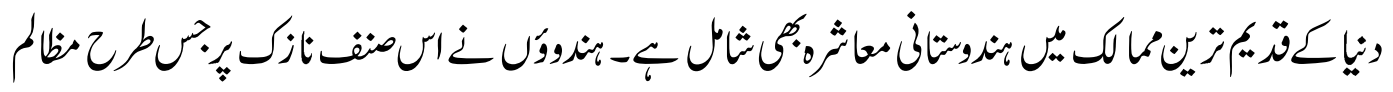

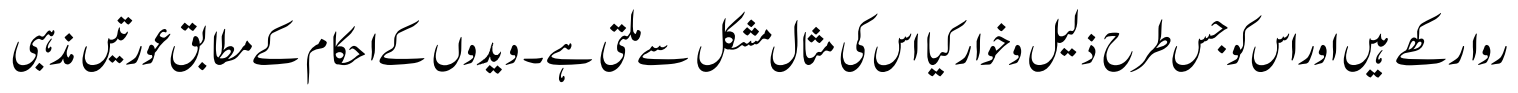

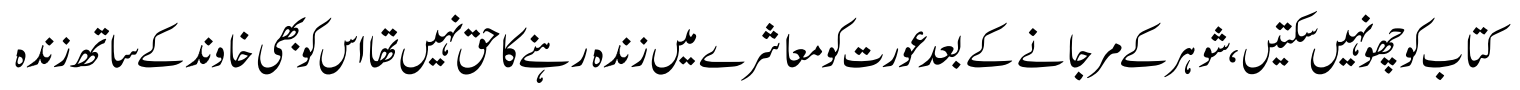

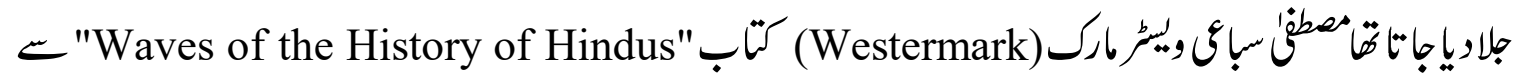

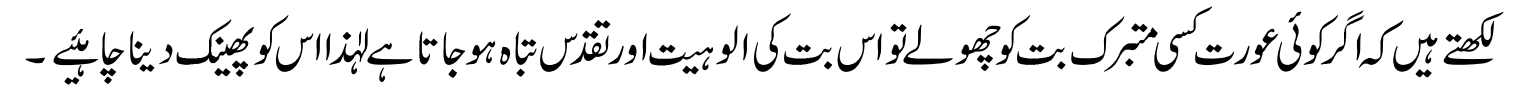

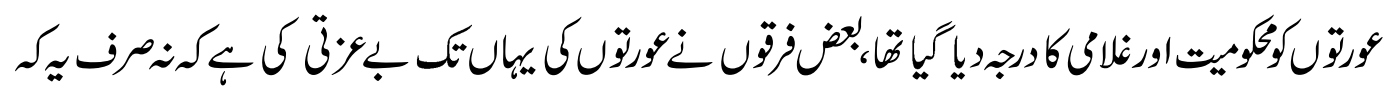

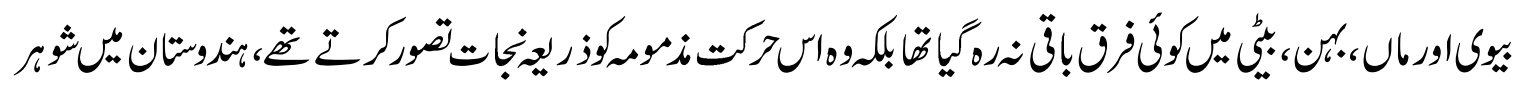

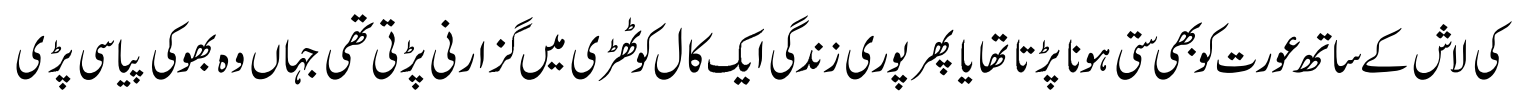

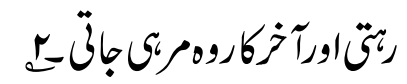

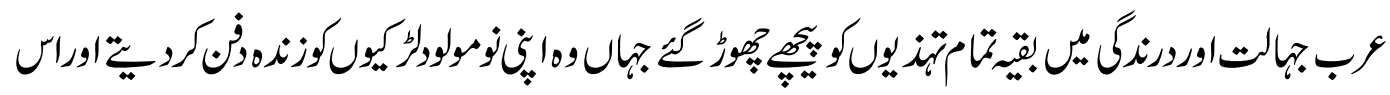

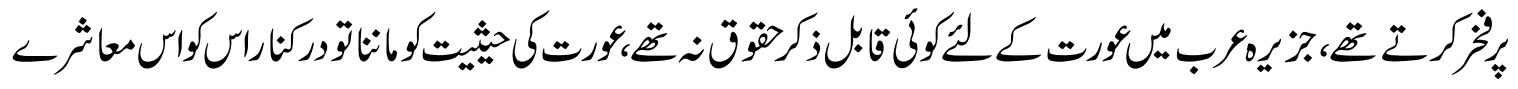

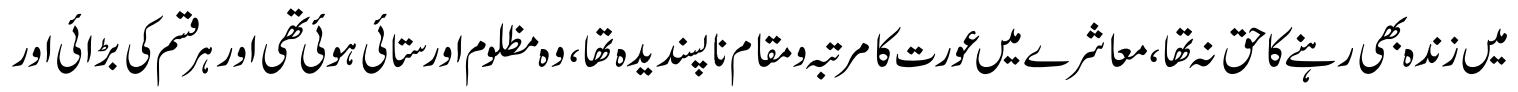

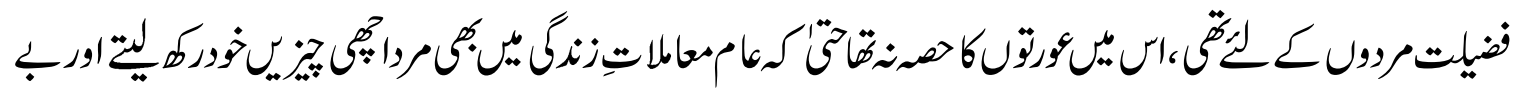

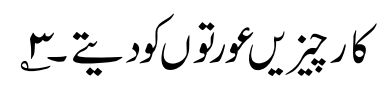

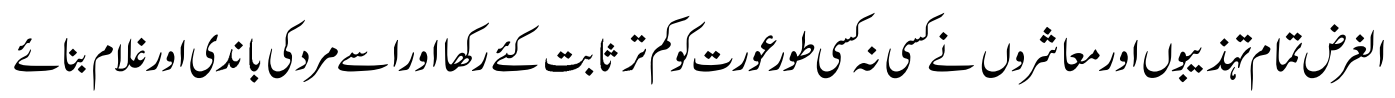




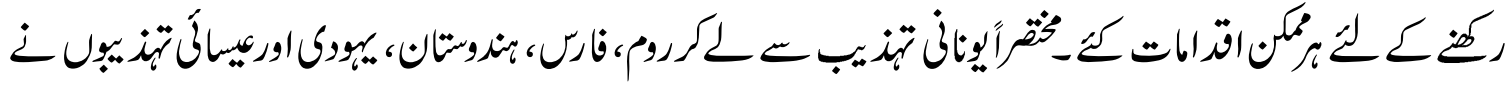

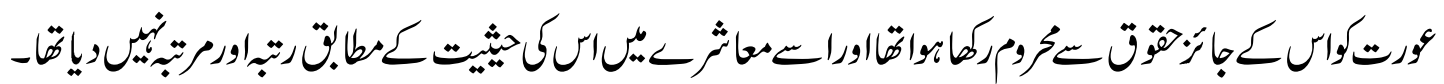

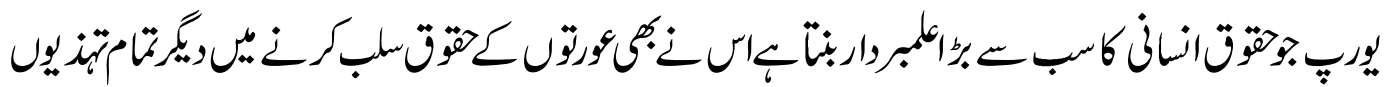

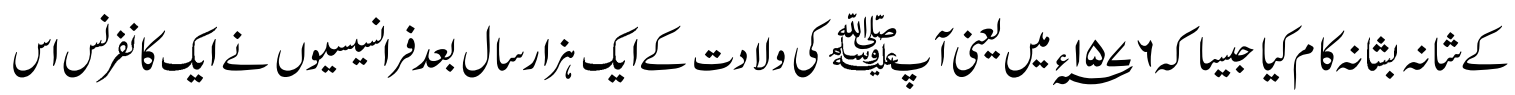

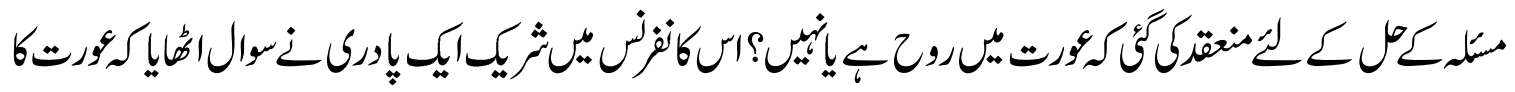

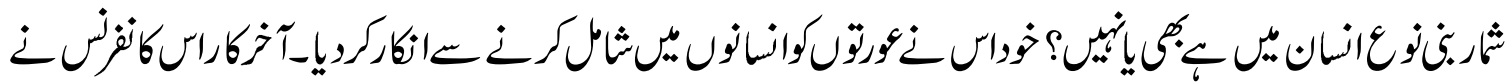

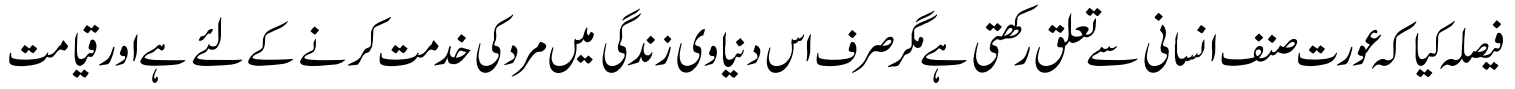

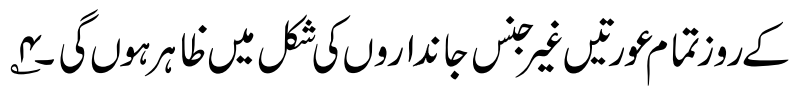

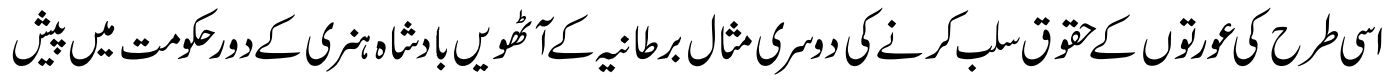

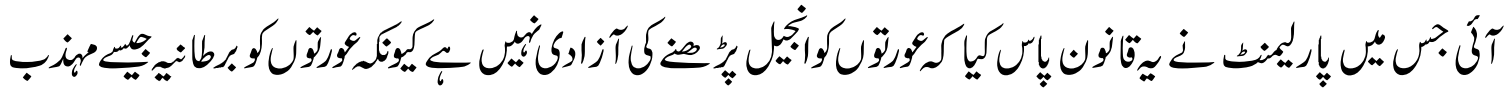

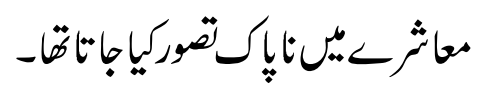

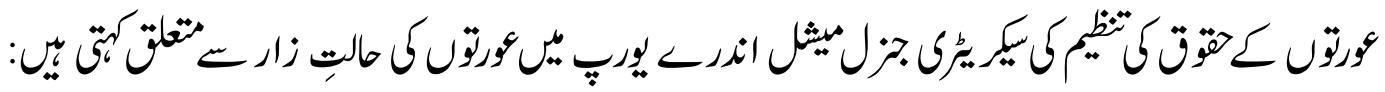

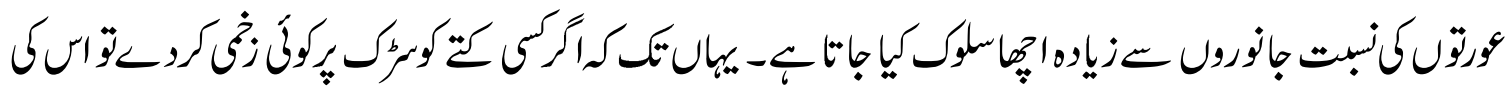

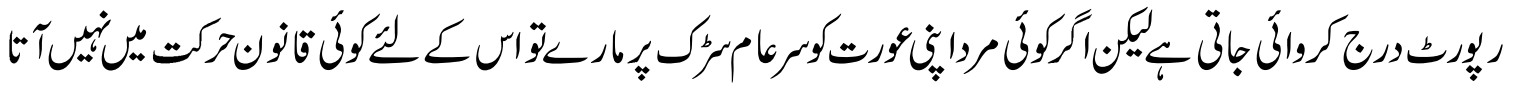

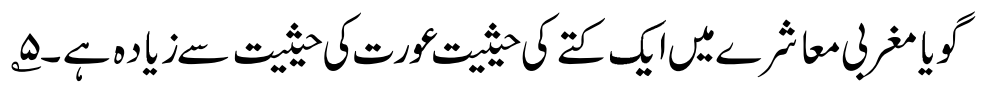

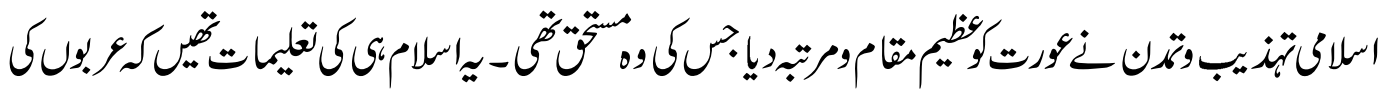

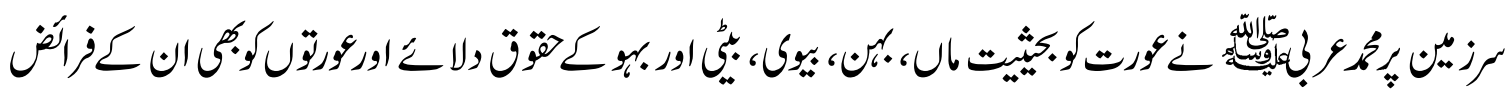

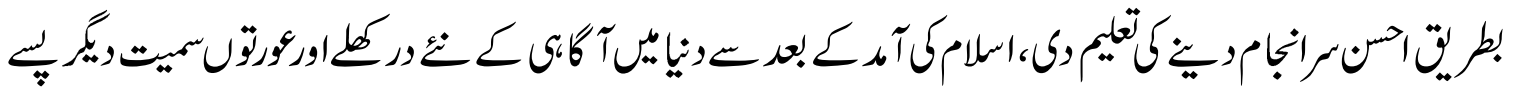

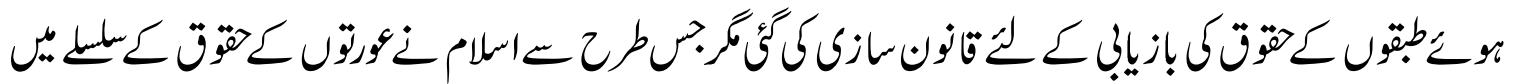

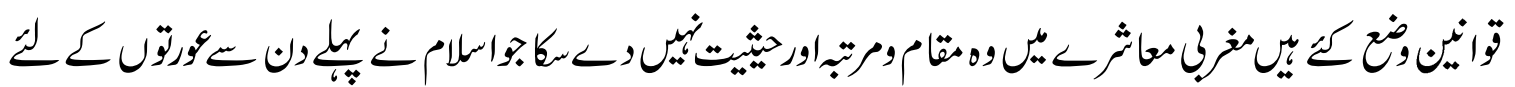




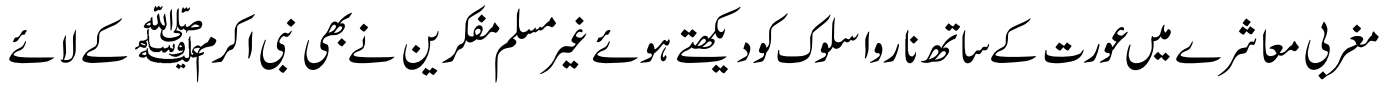

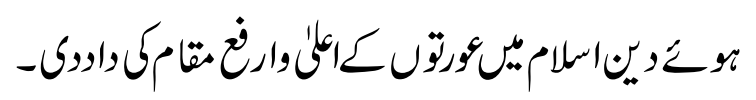

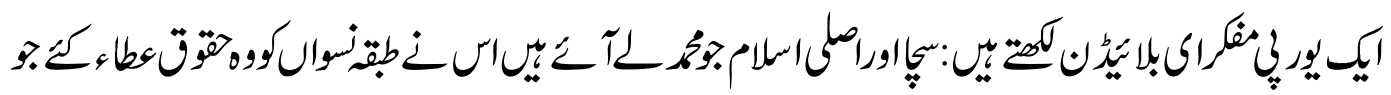

$$
\text { اس }
$$

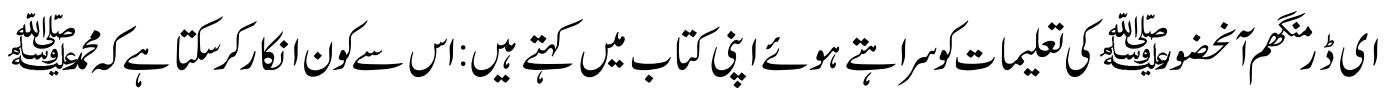

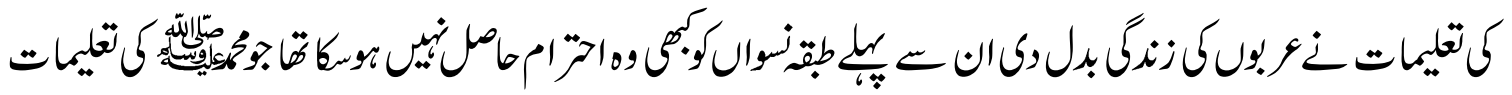

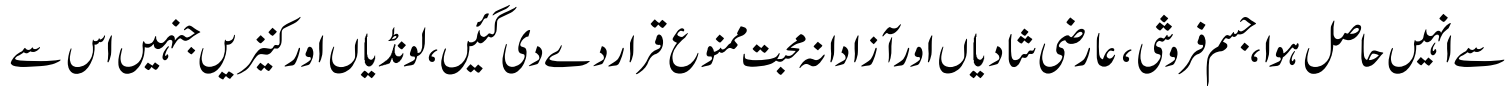

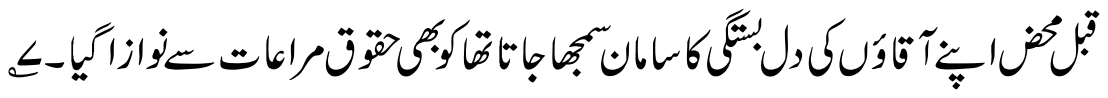

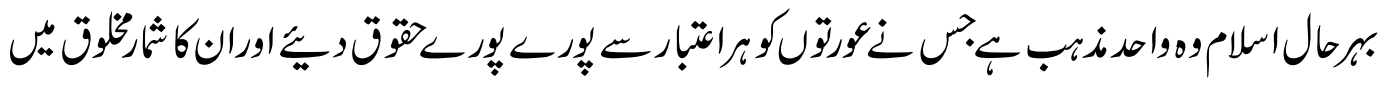

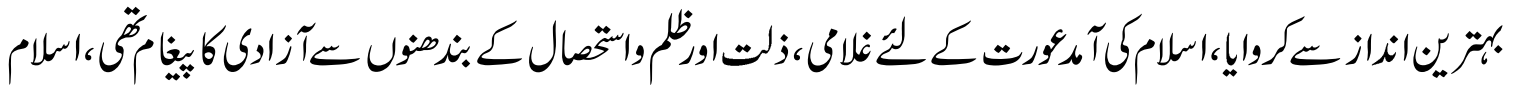

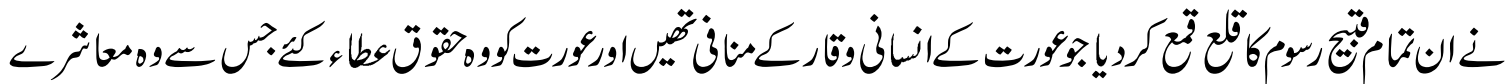

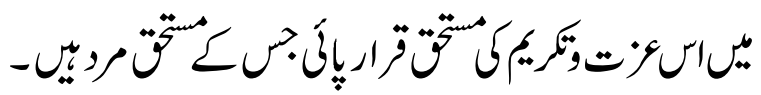

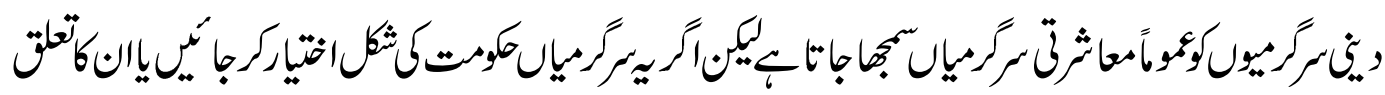

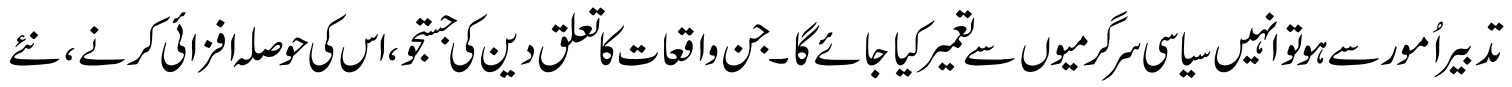

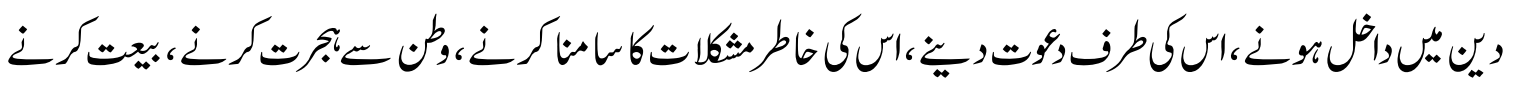

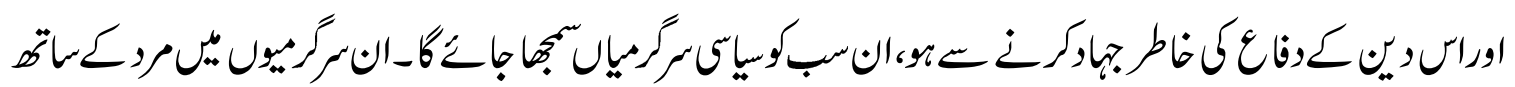

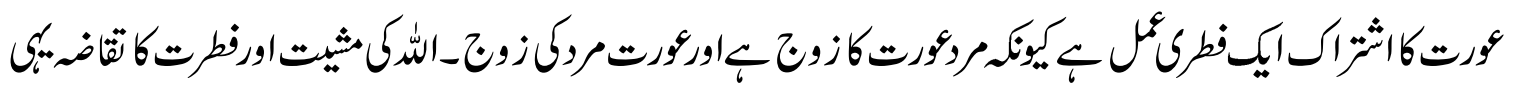

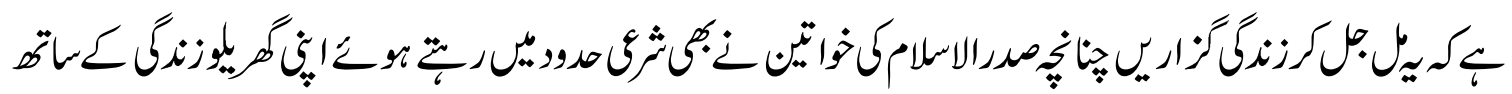

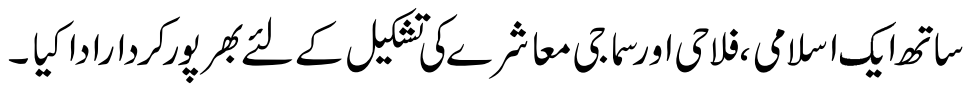

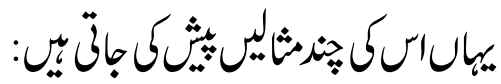

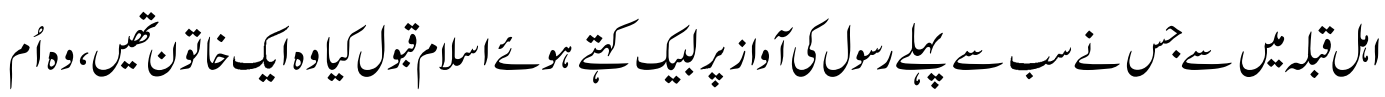




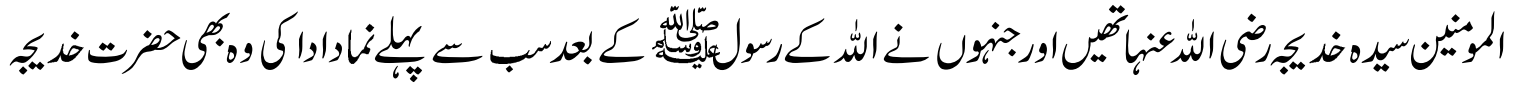

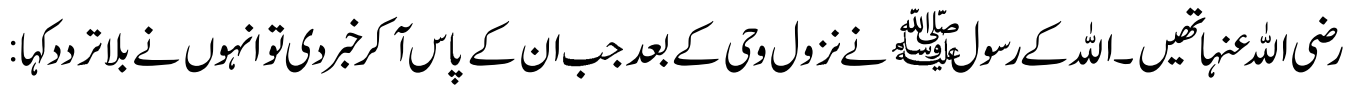

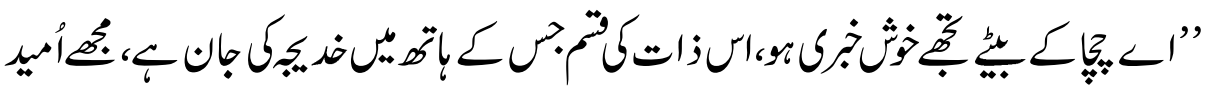

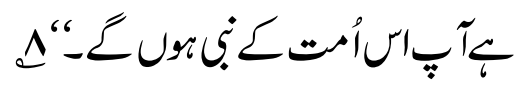

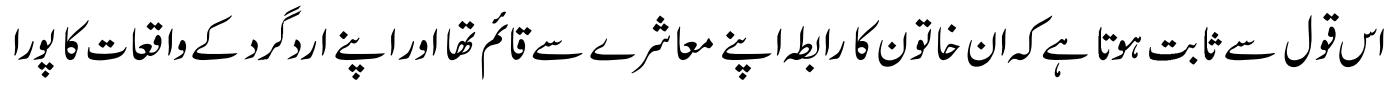

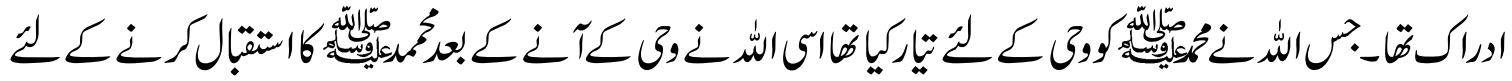

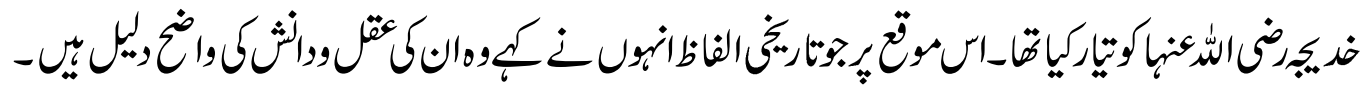

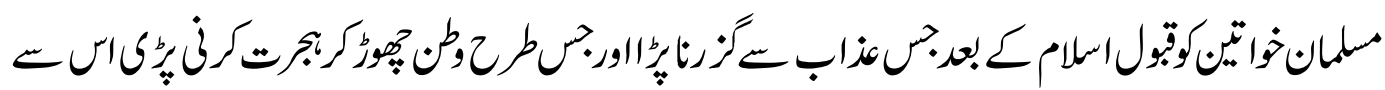

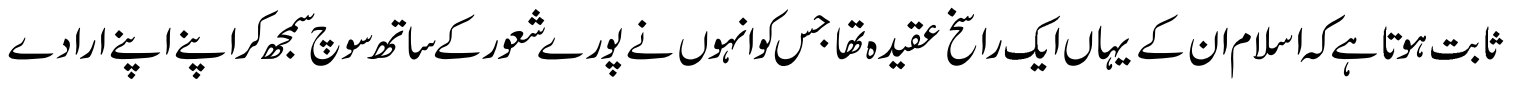

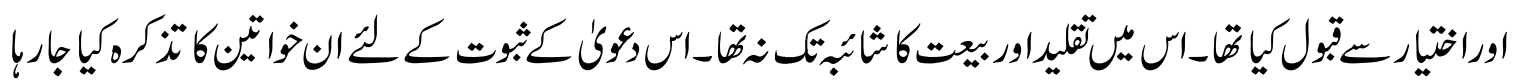

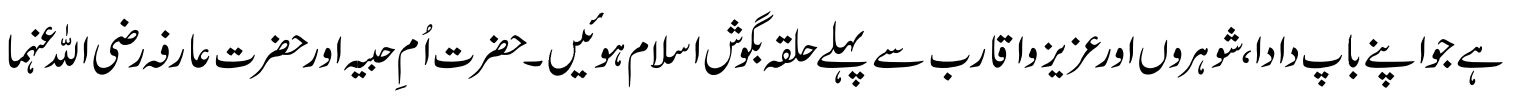

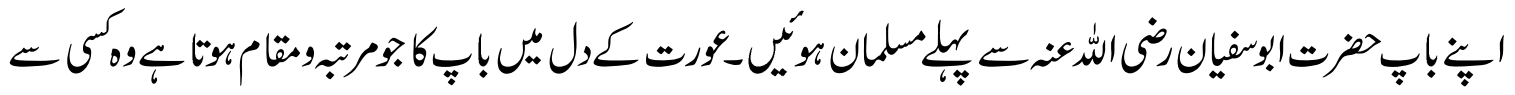

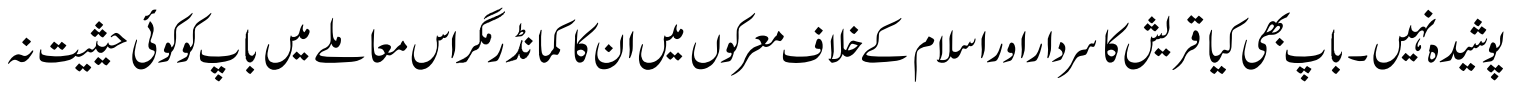

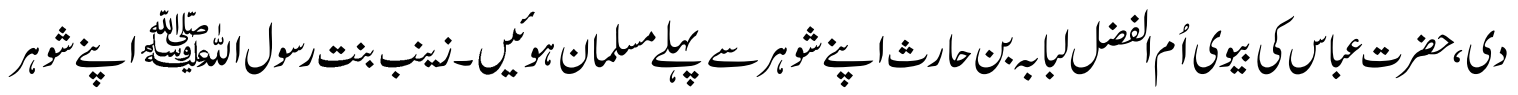

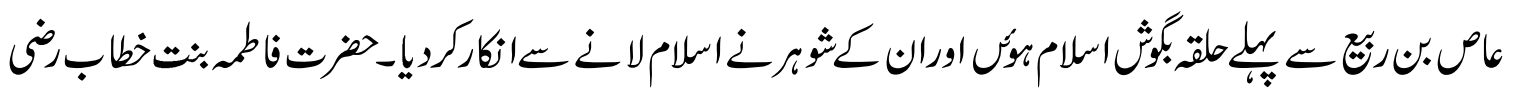

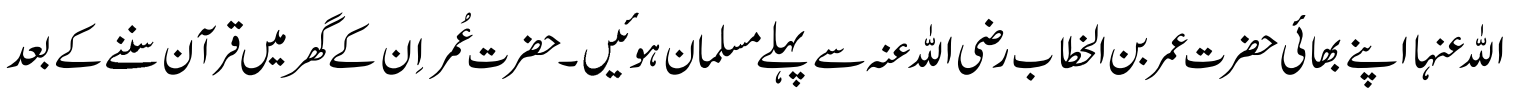
مسلمان بوك

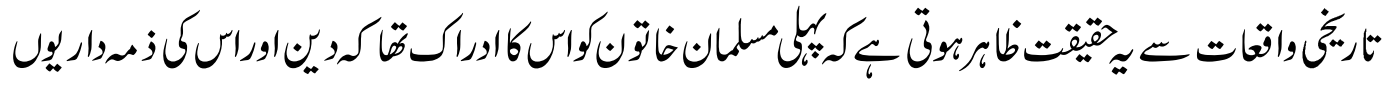

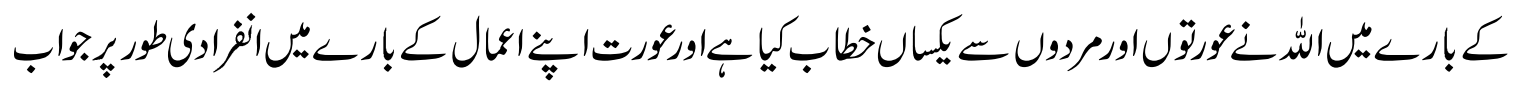

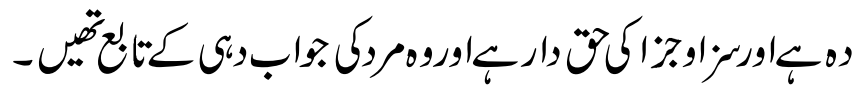

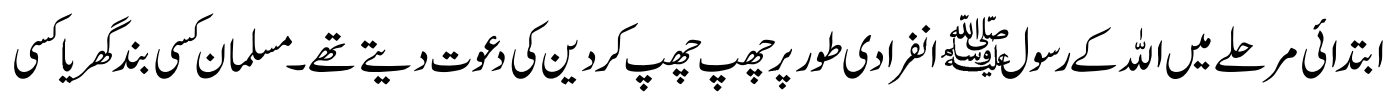




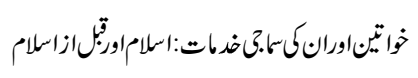

$r$

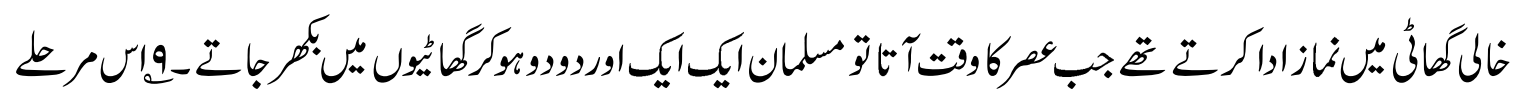

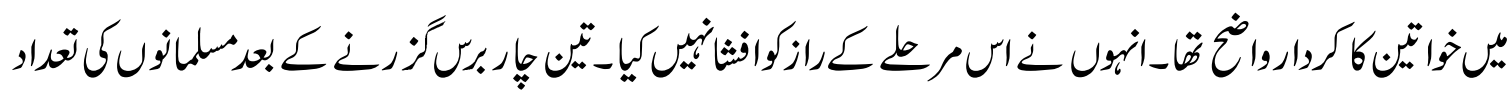

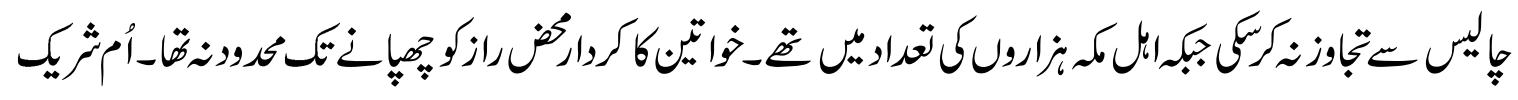

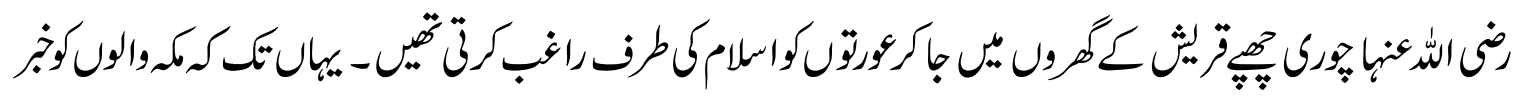

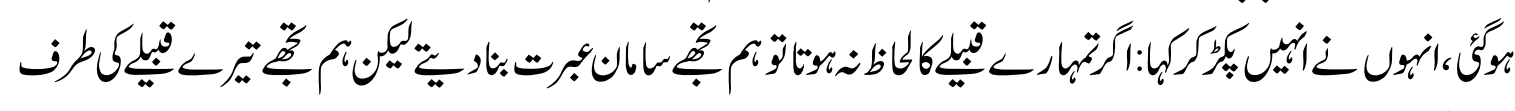

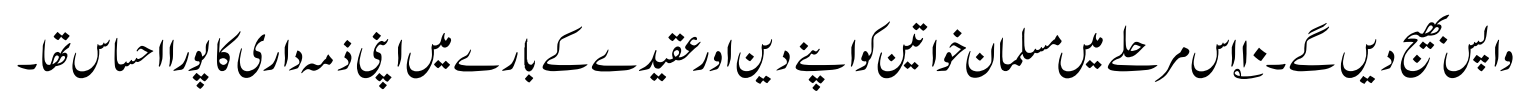

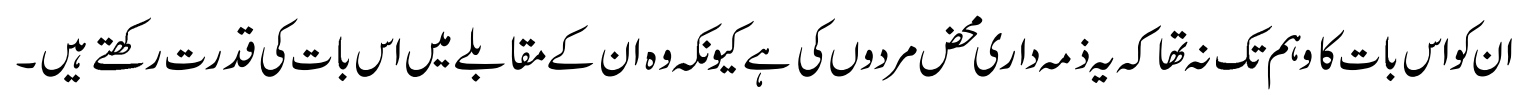

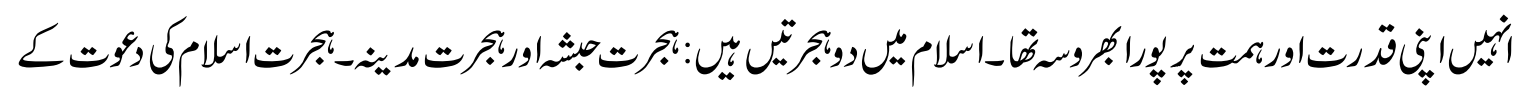

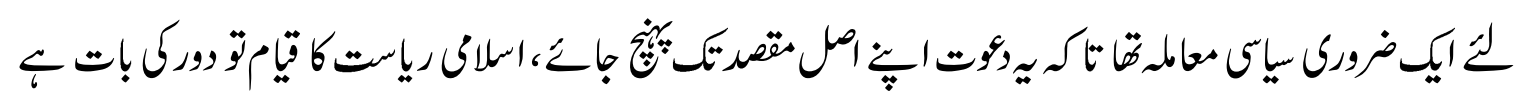

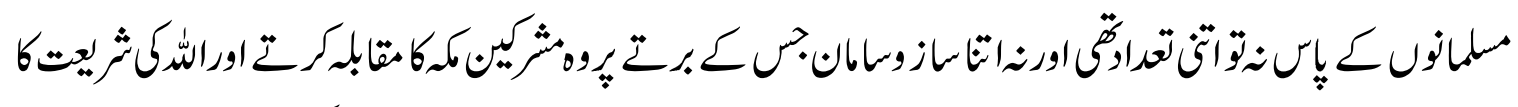

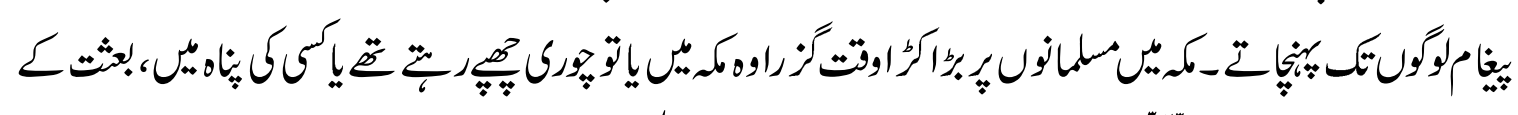

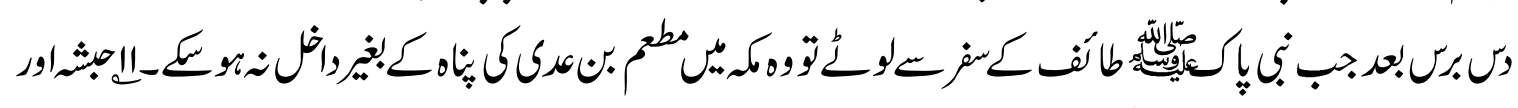

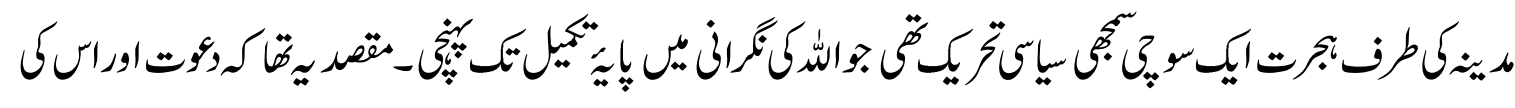

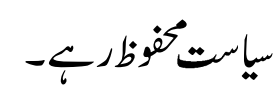

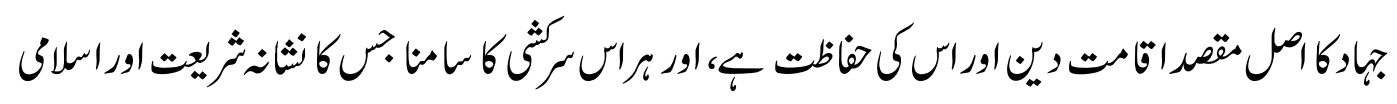

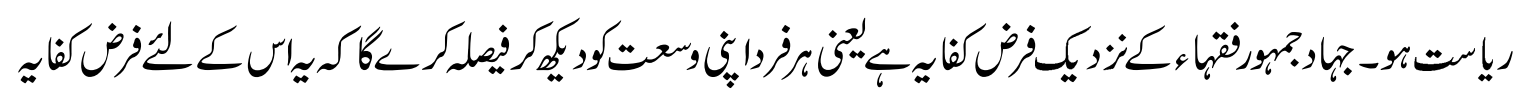

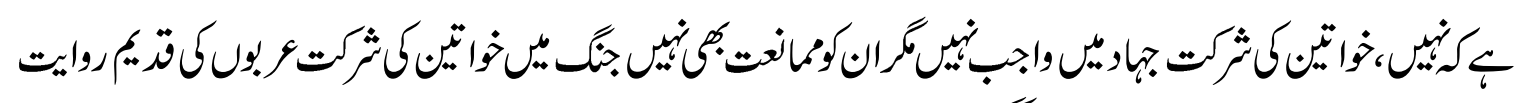

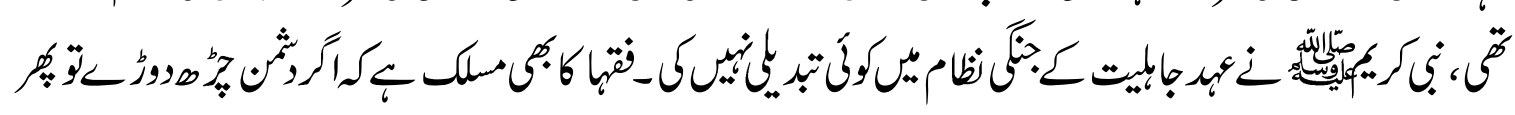

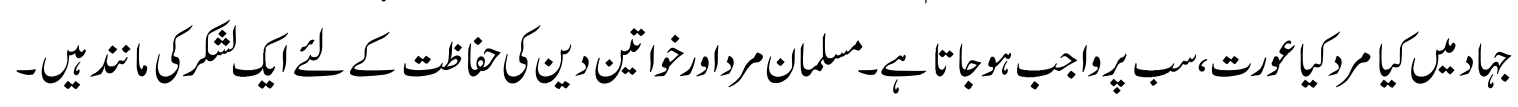

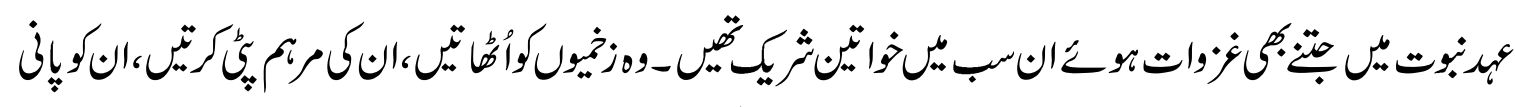

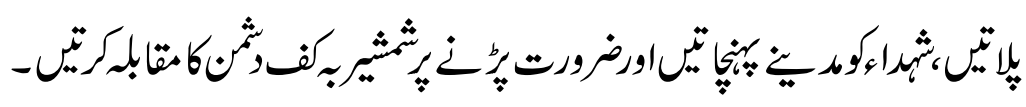




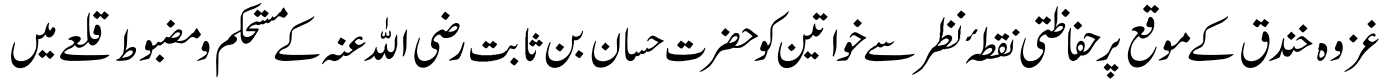

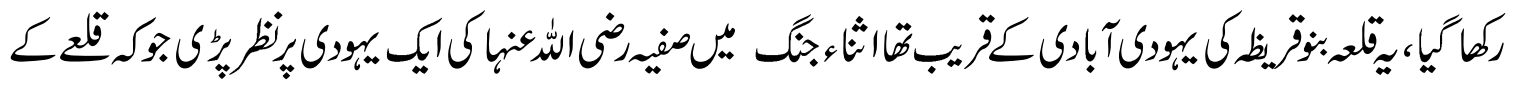

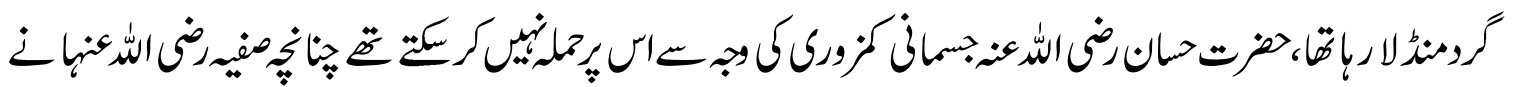

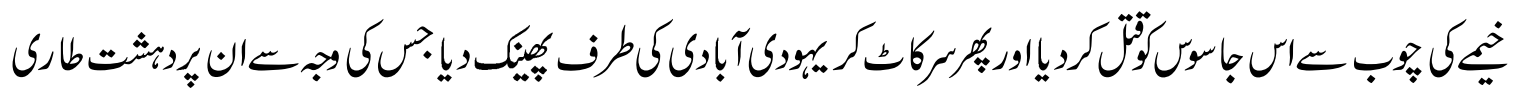

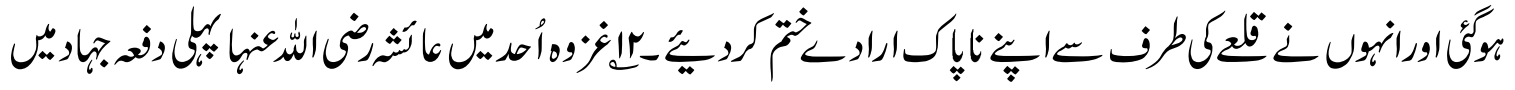

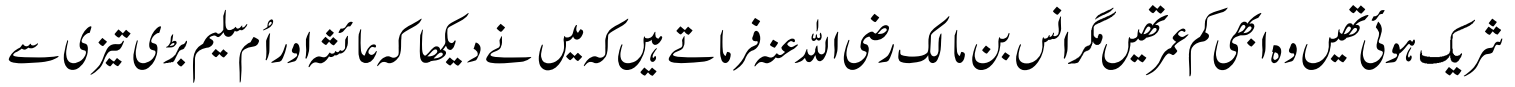

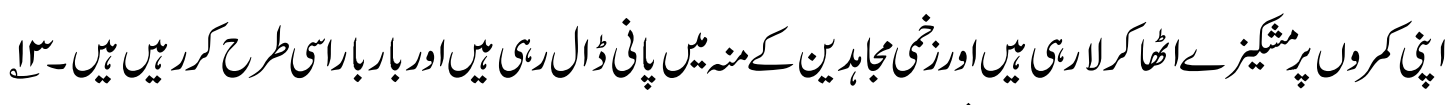

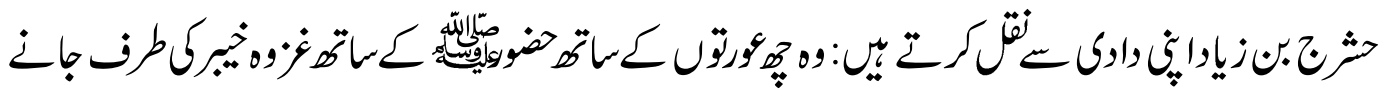

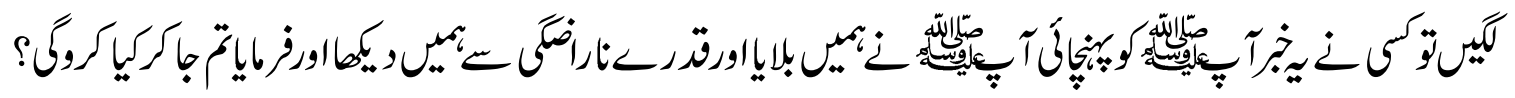

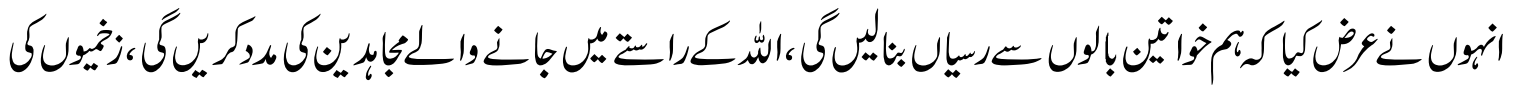

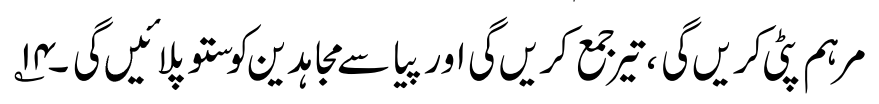

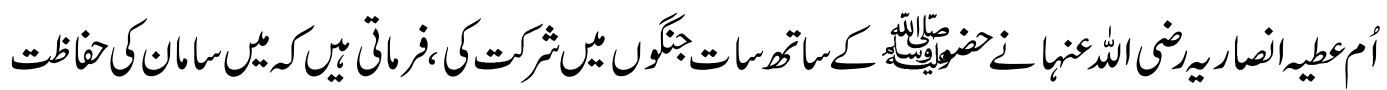

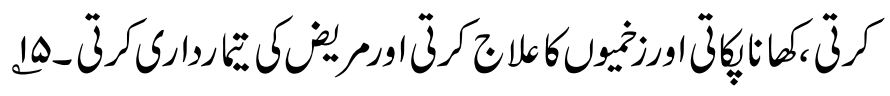

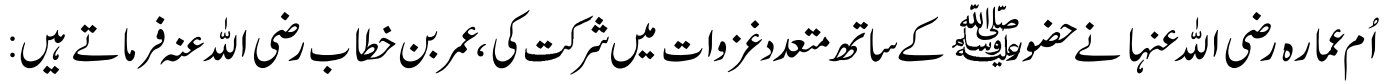

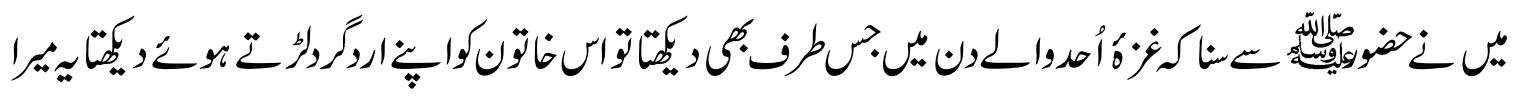

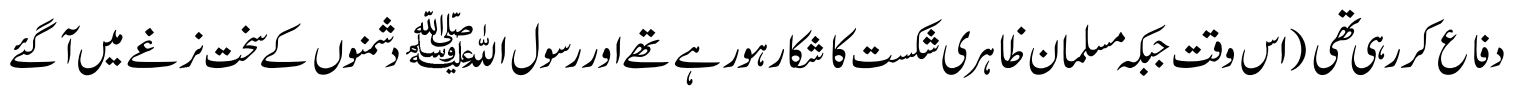

$$
\text { 14- } \ddot{E}
$$

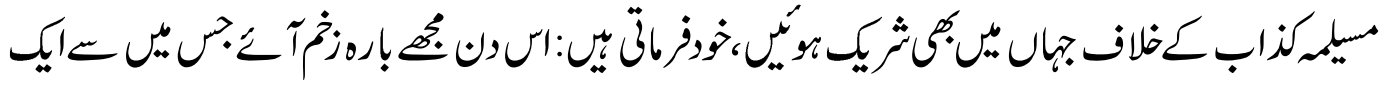

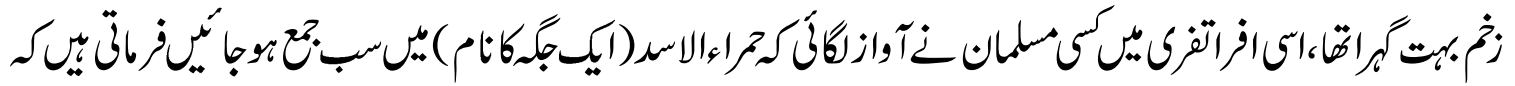

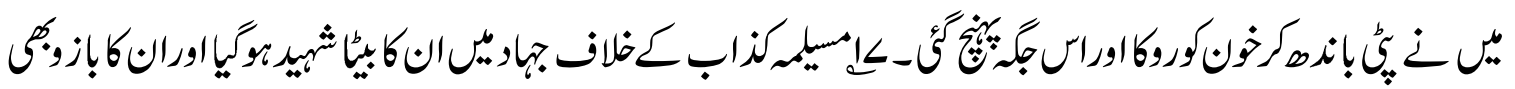




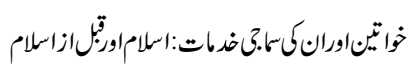

m

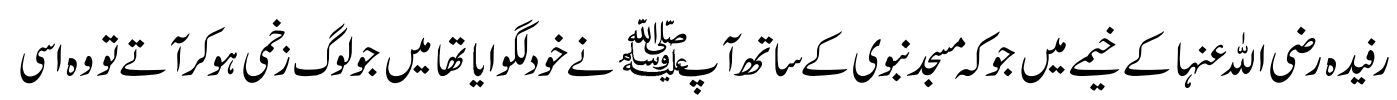

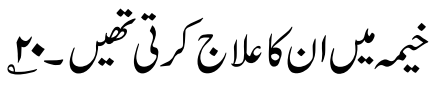

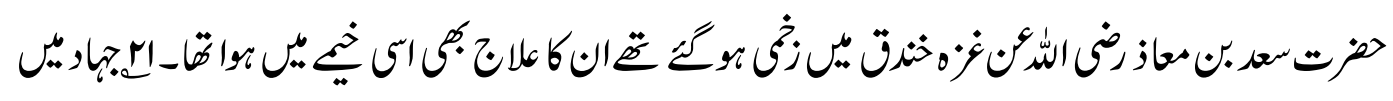

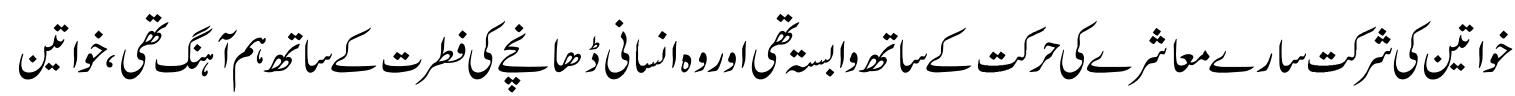

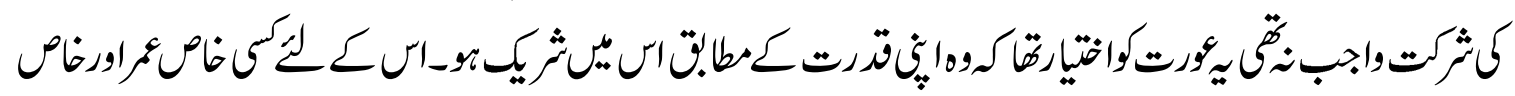

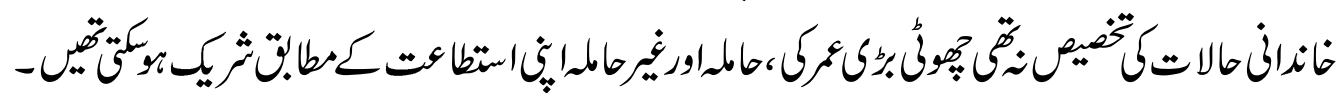

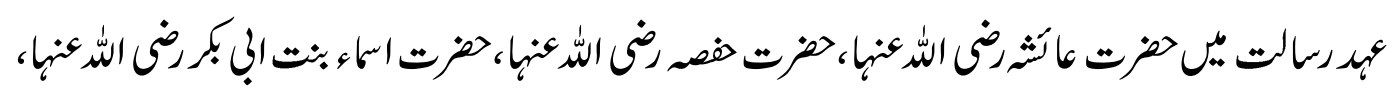

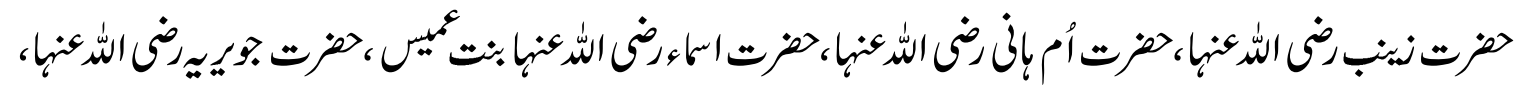

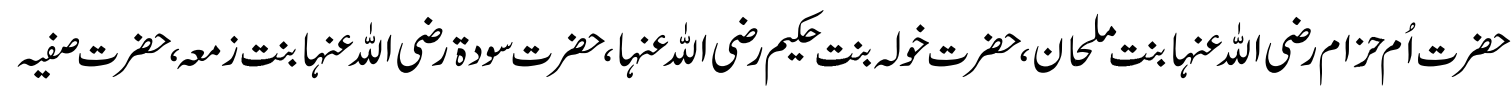

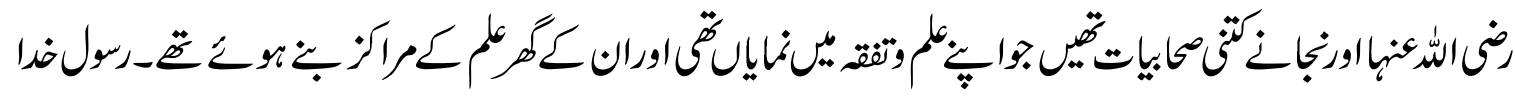

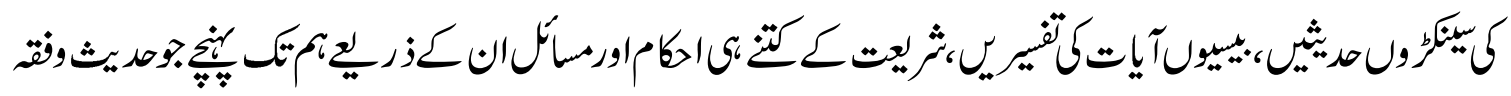

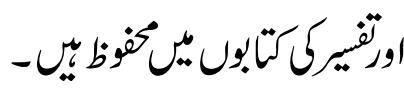

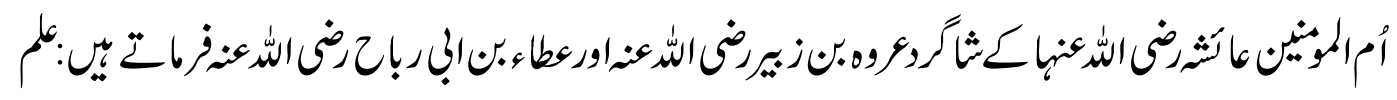

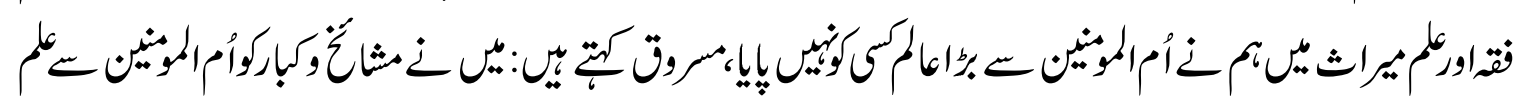
Ir- 156 -

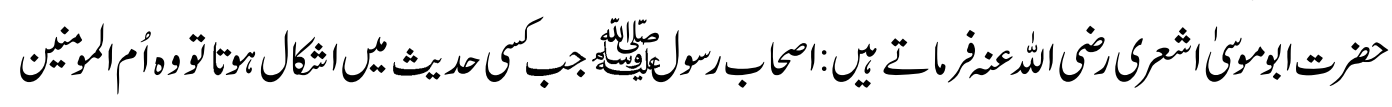

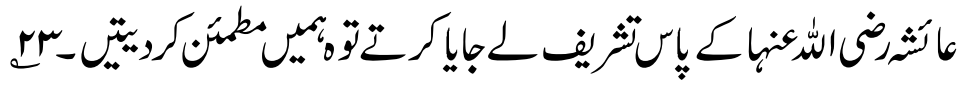

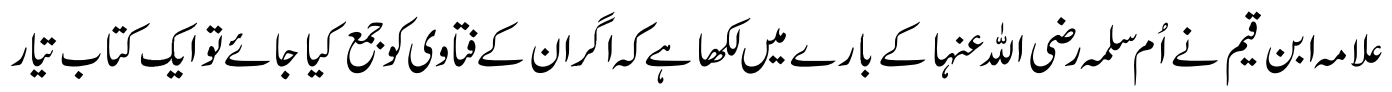

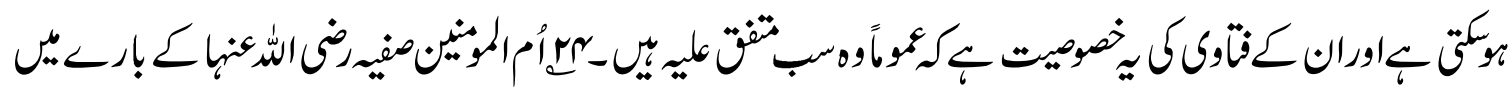

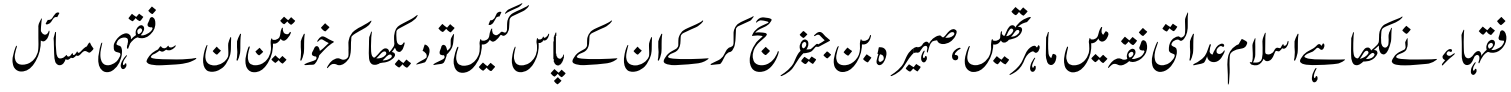

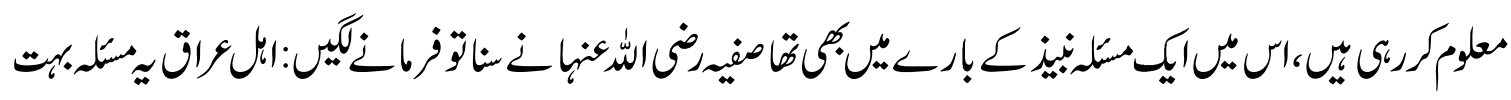




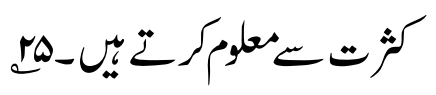

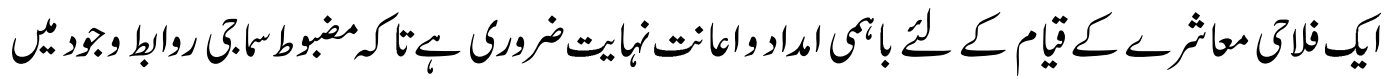

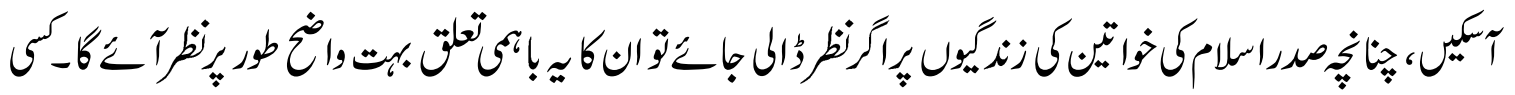

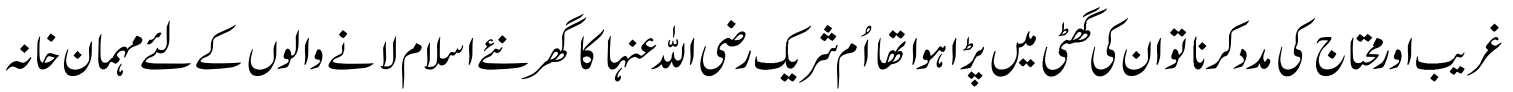

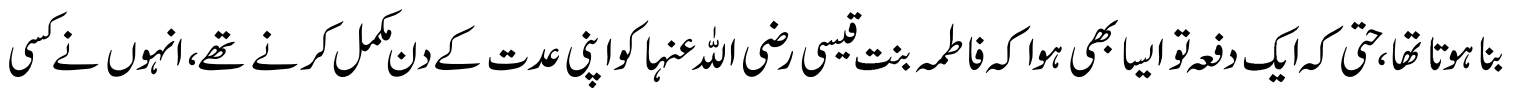

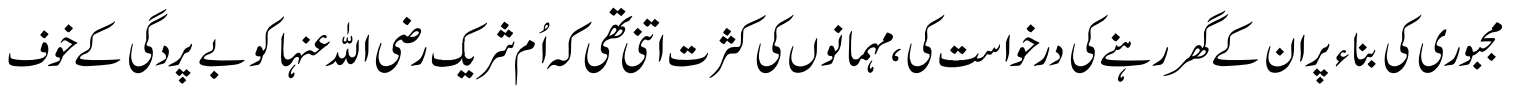

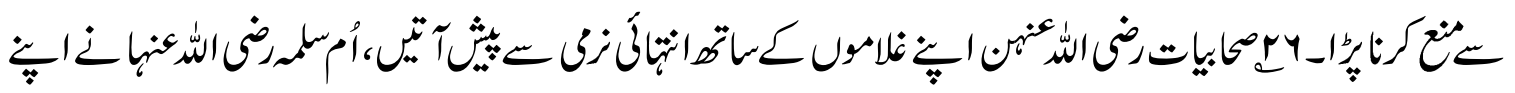

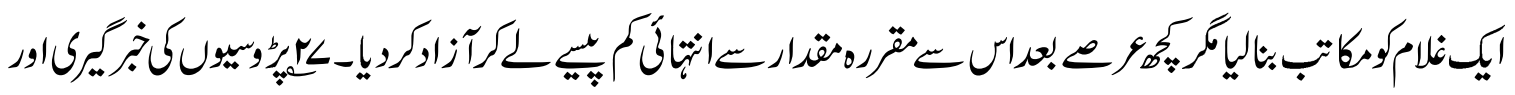

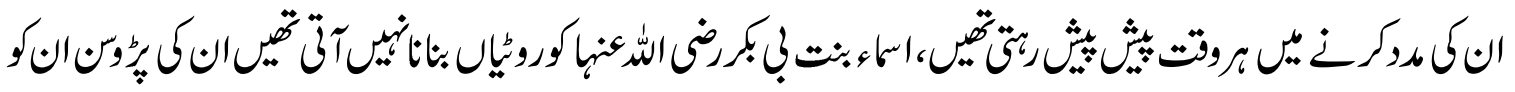

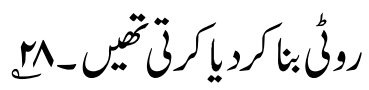

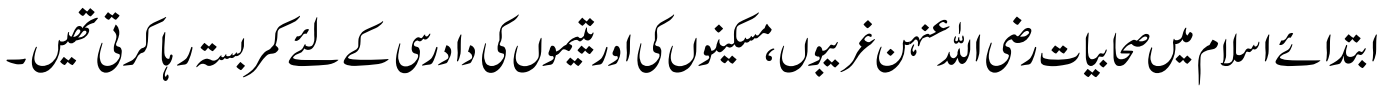

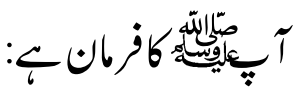
تزبم:

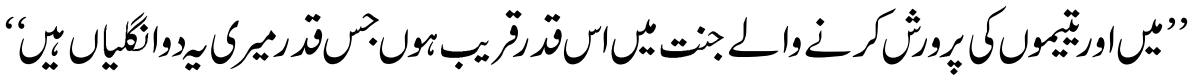

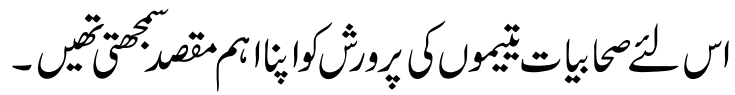

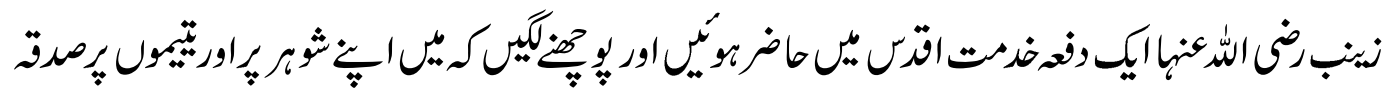

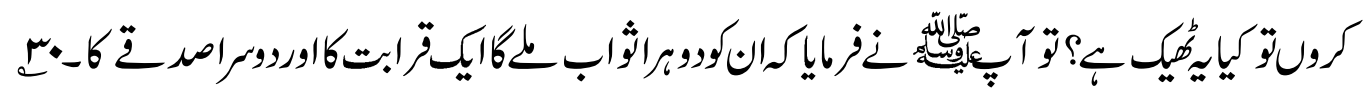

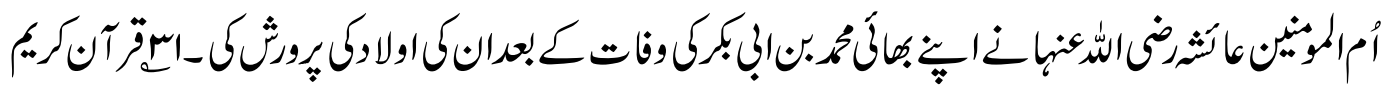

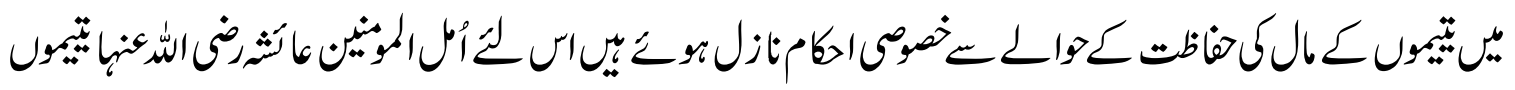

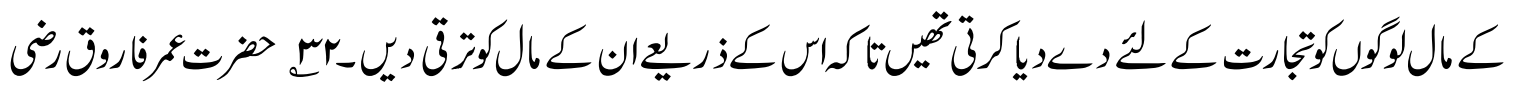

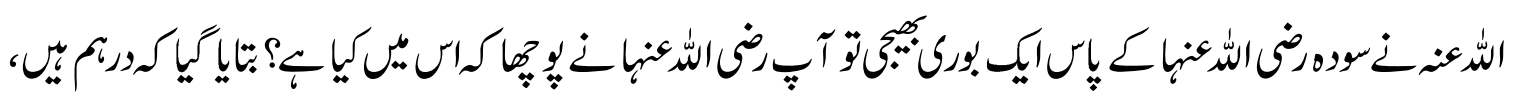




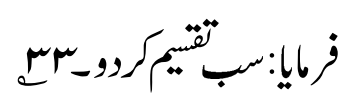

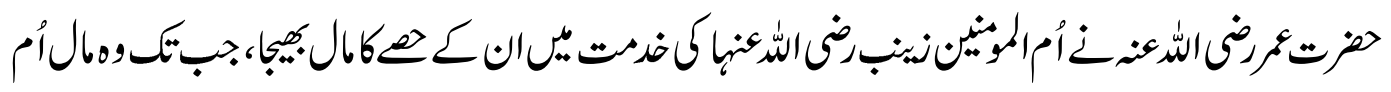

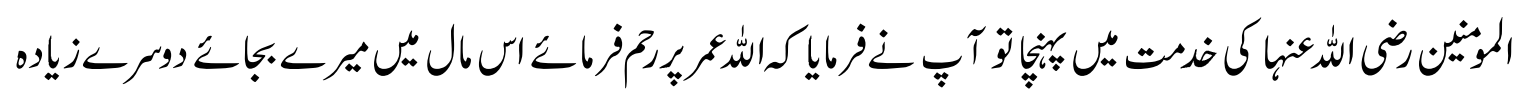

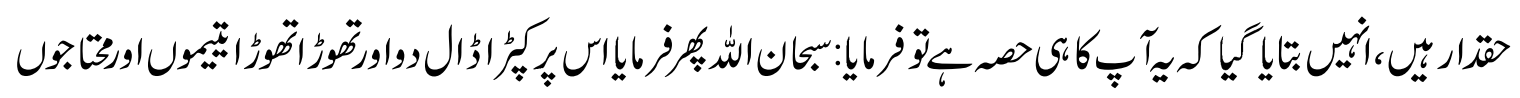

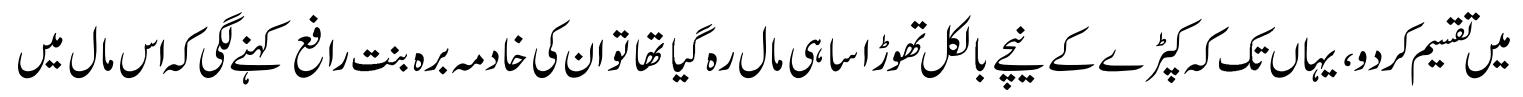

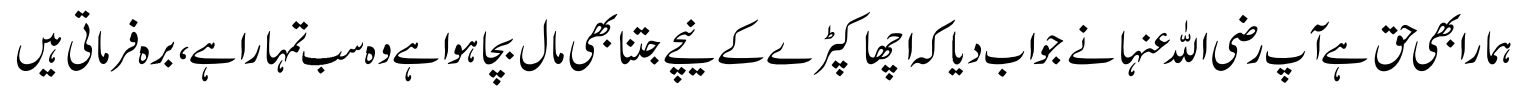

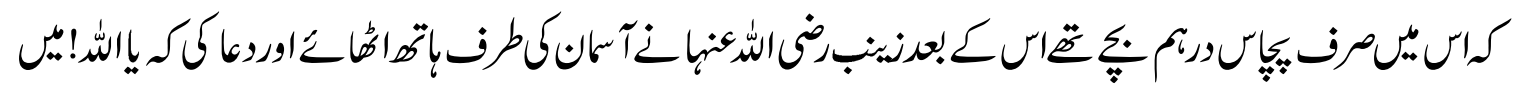

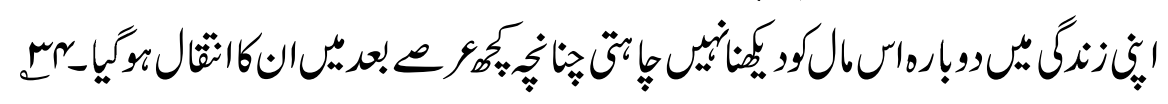

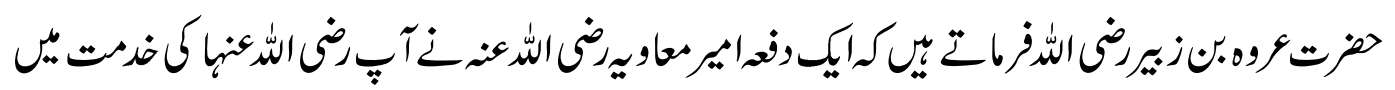

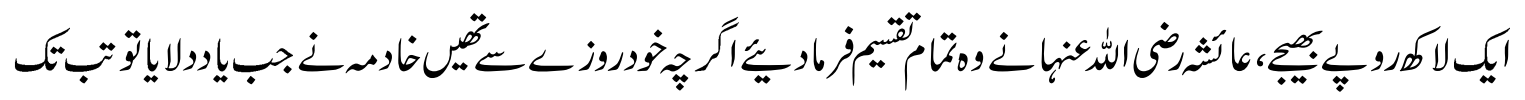

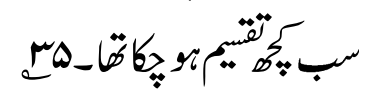

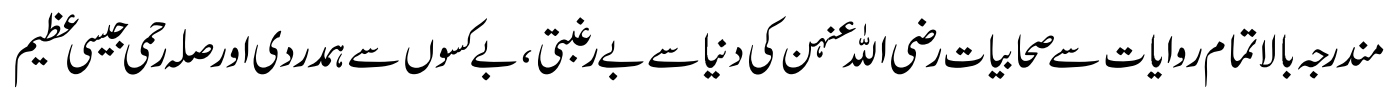

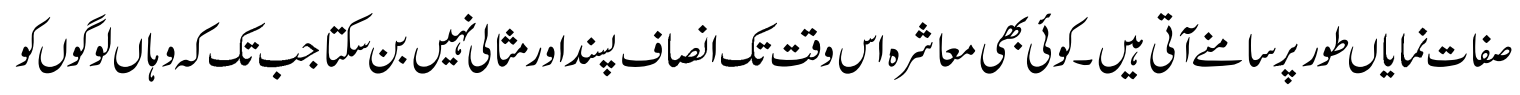

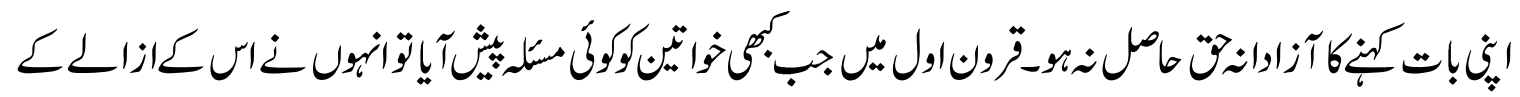

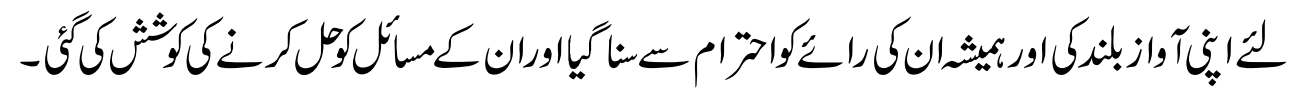

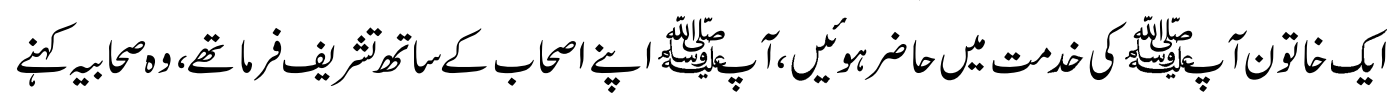

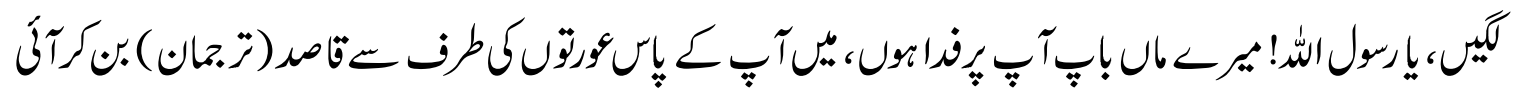

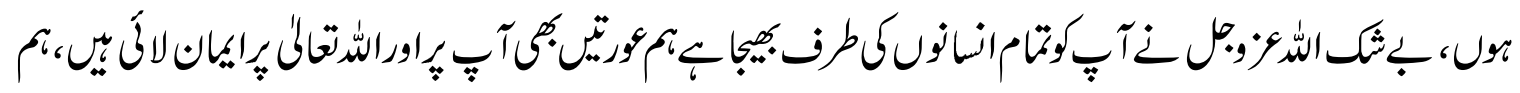

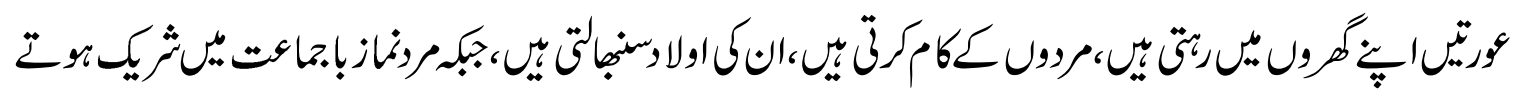

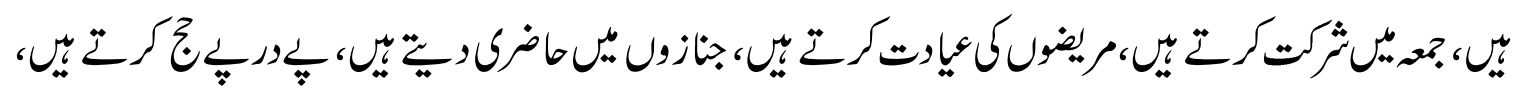

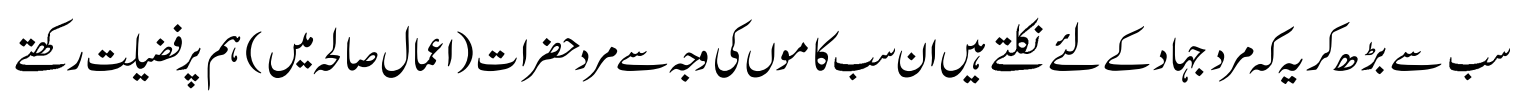




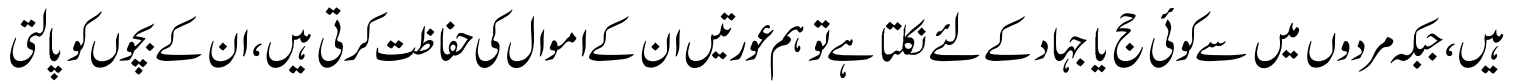

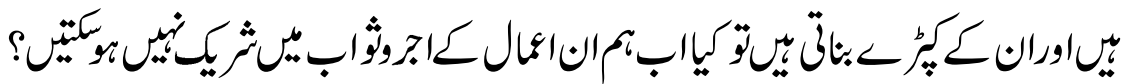

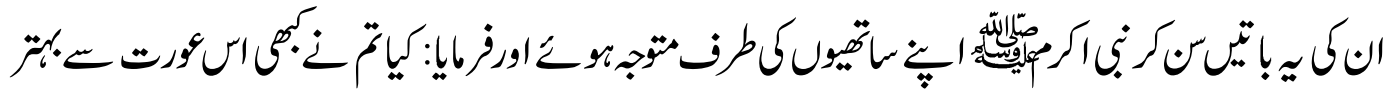

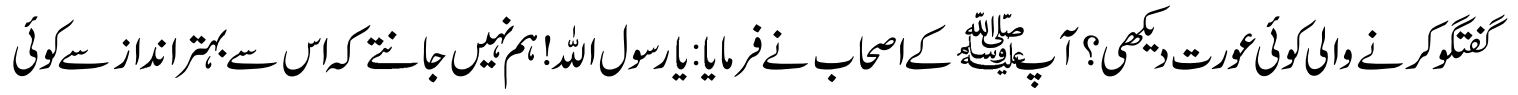

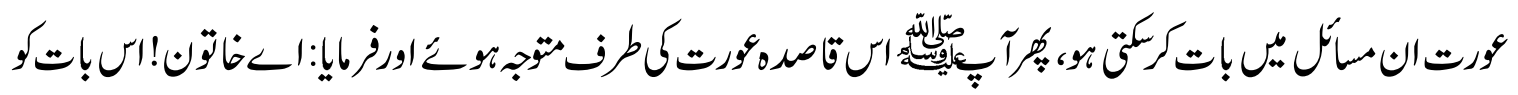

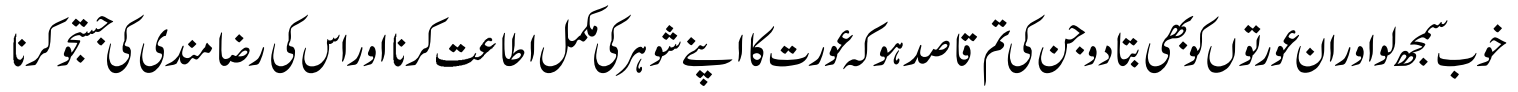

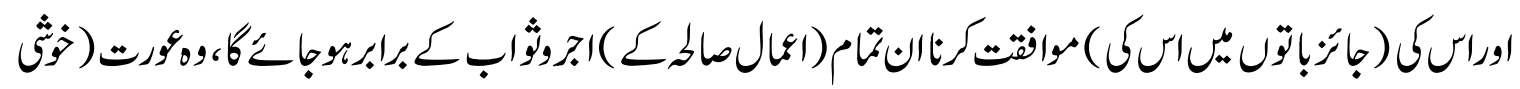

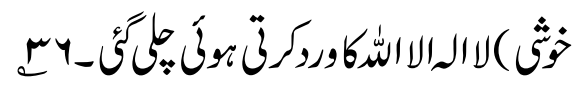

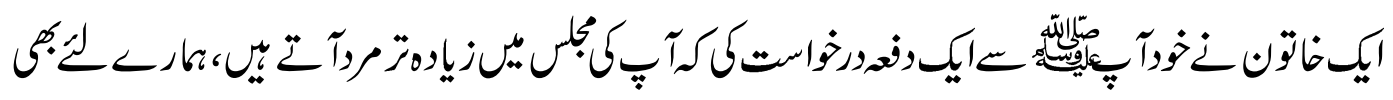

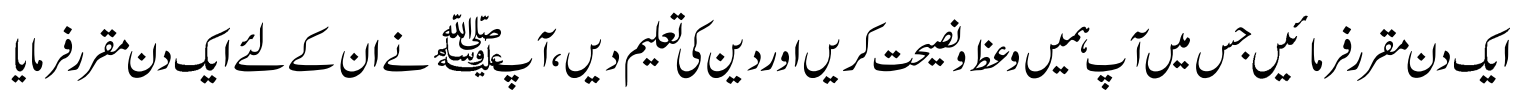

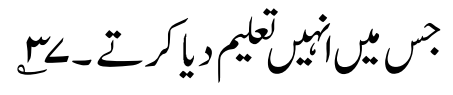

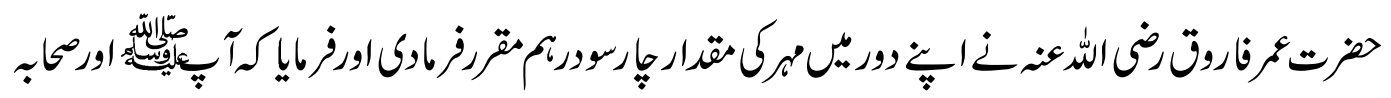

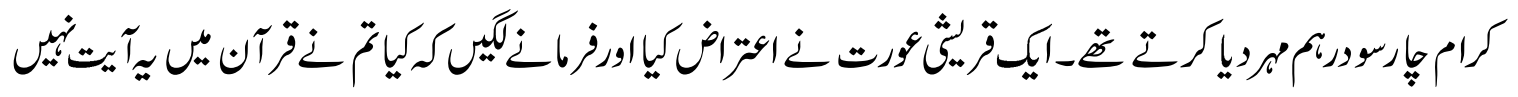

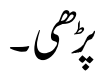
تקجم:

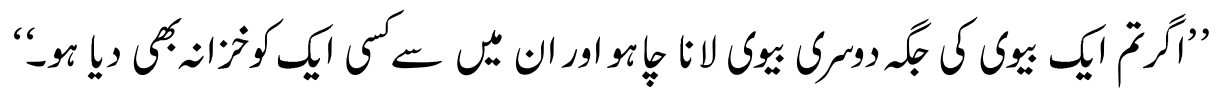
(r.:الناء)

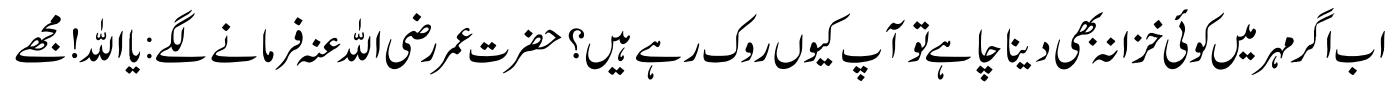

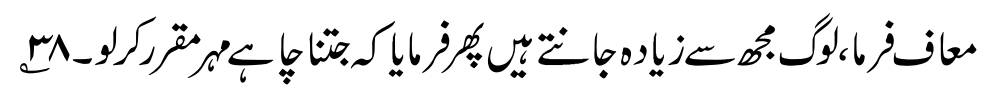

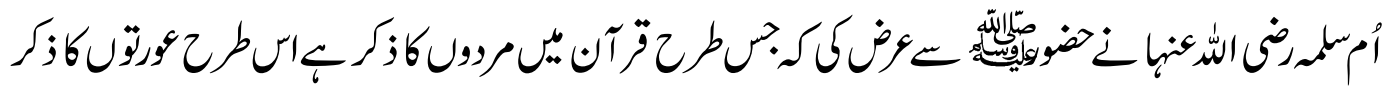

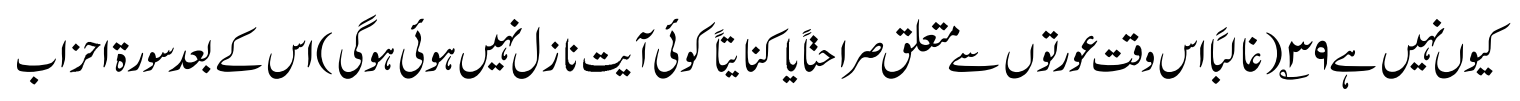




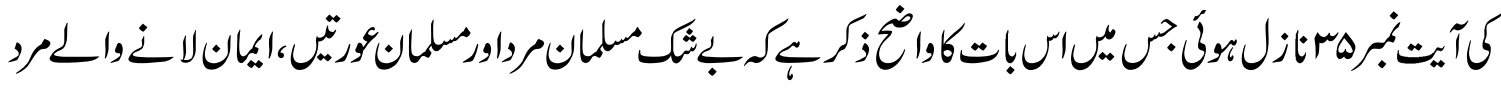

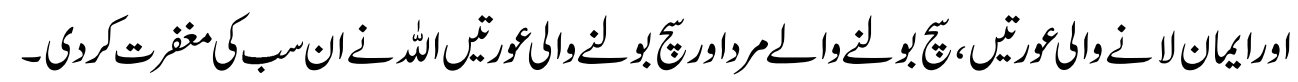

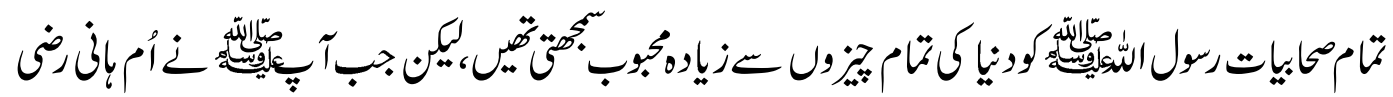

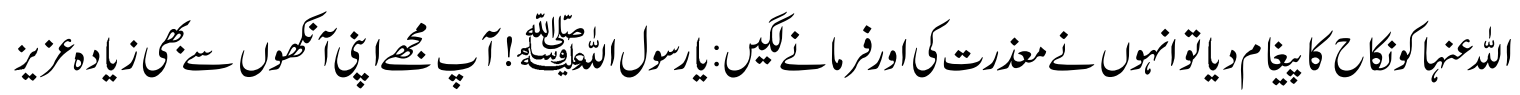

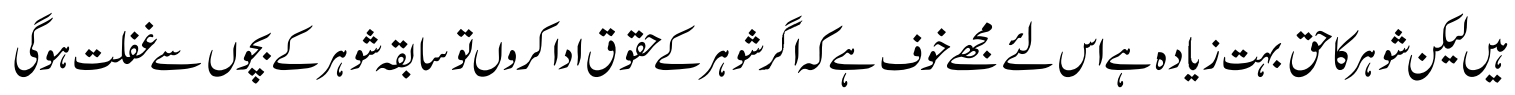

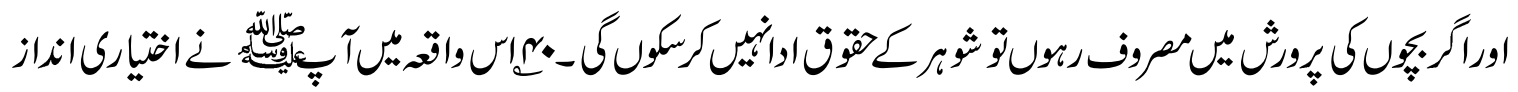

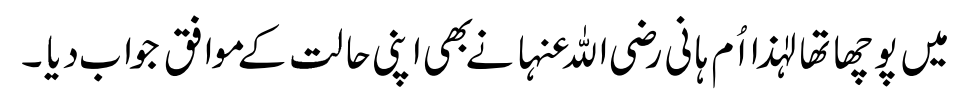

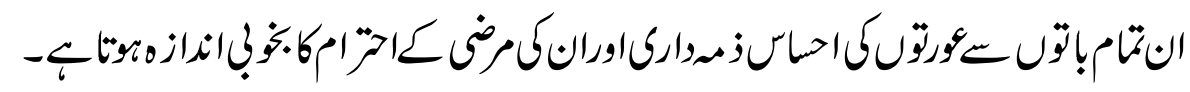

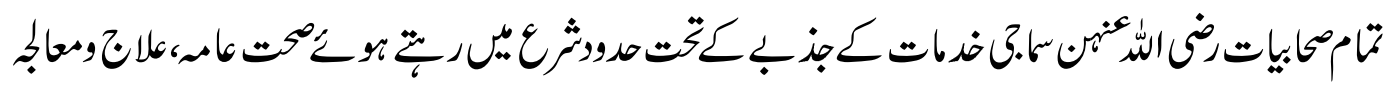

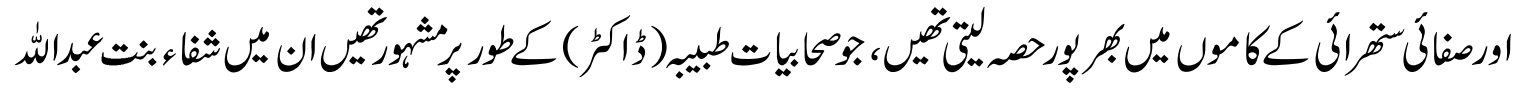

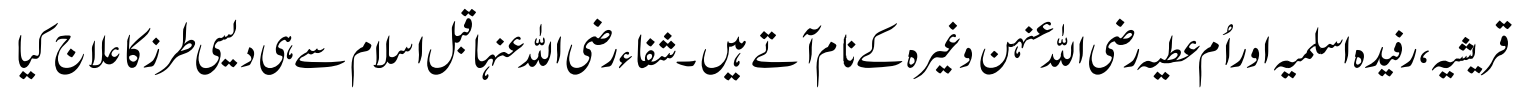

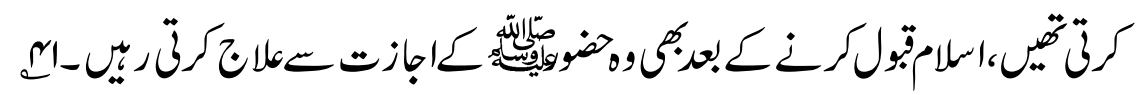

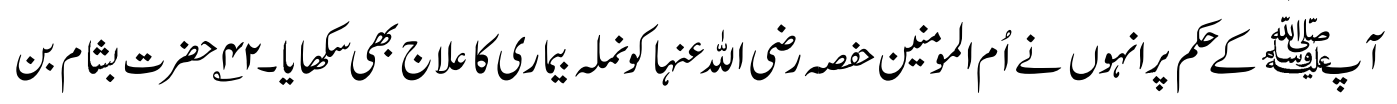

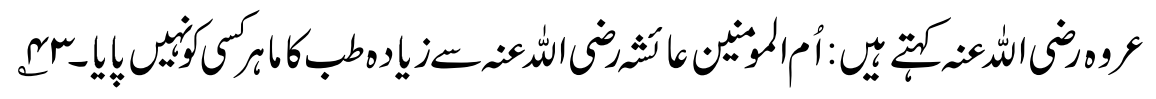

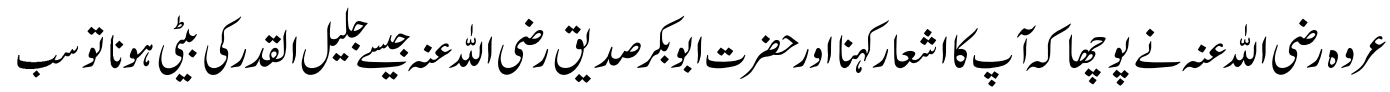

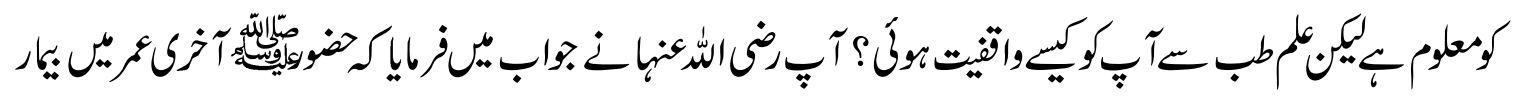

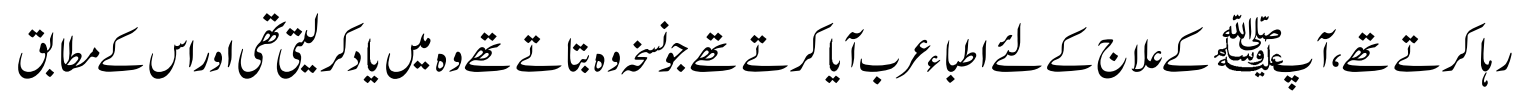
علاجrك

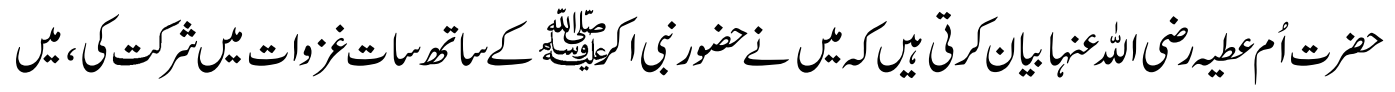

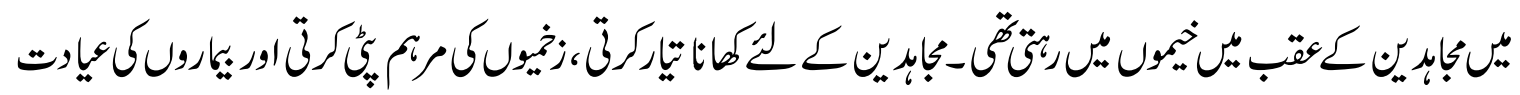
كرن 
re

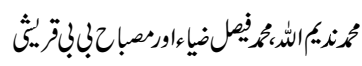

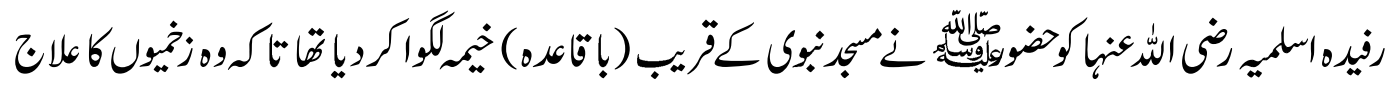

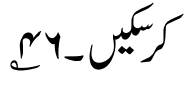

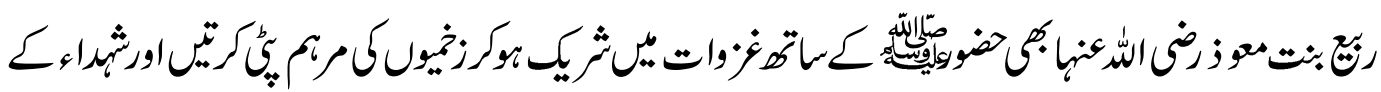

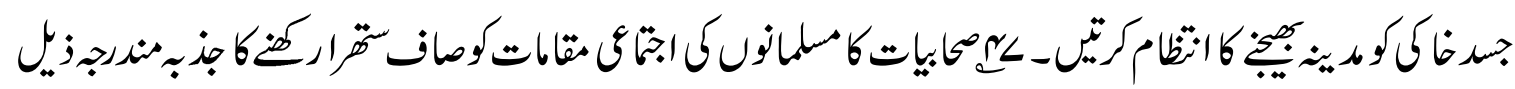

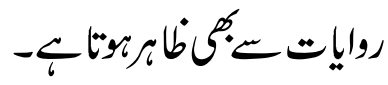

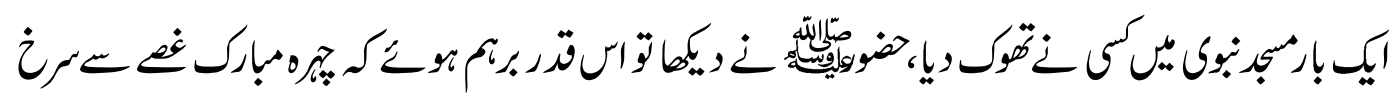

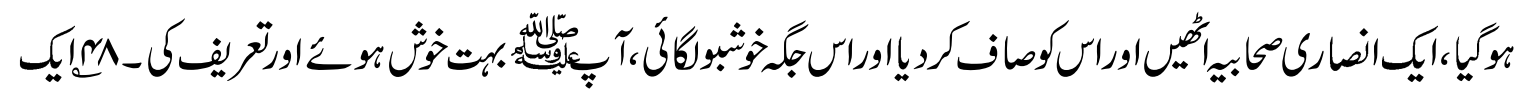

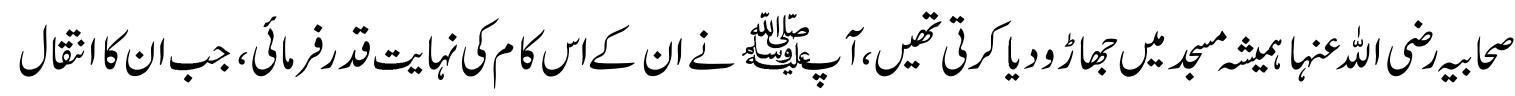

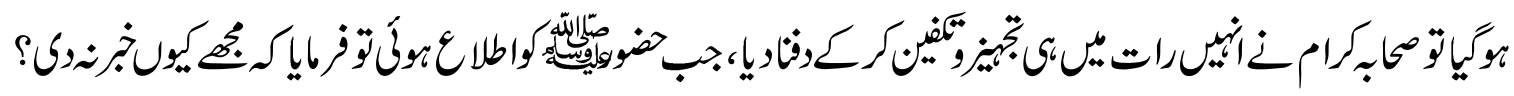

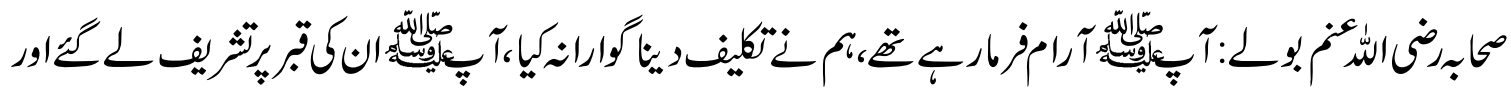

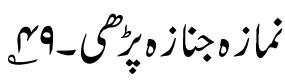

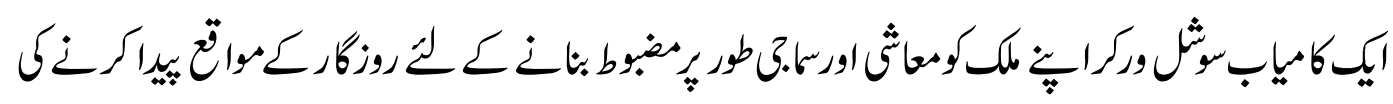

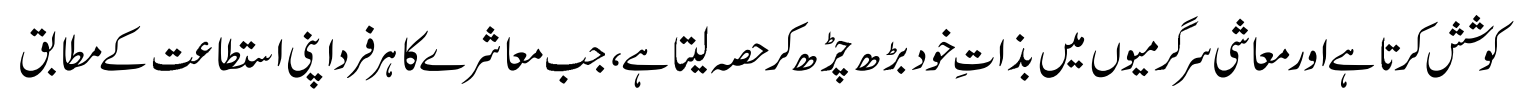

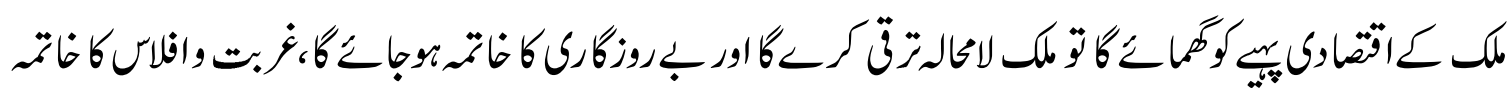

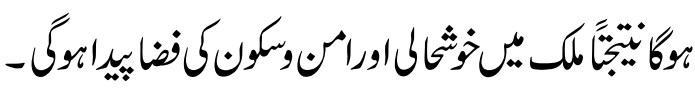

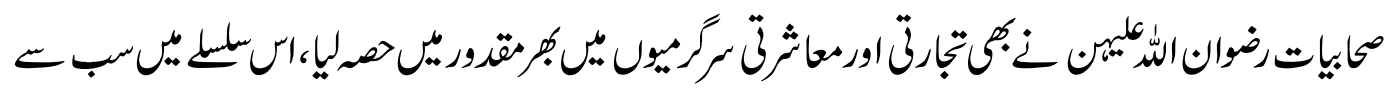

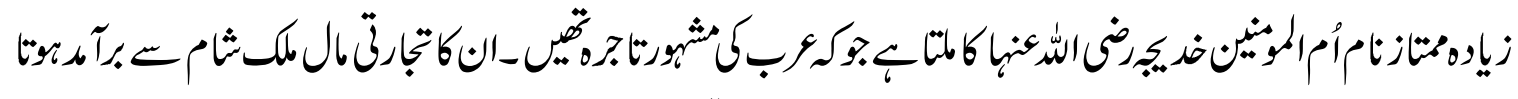

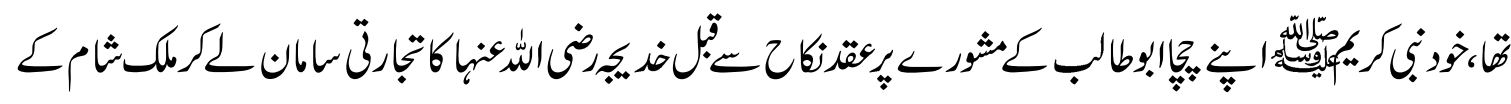

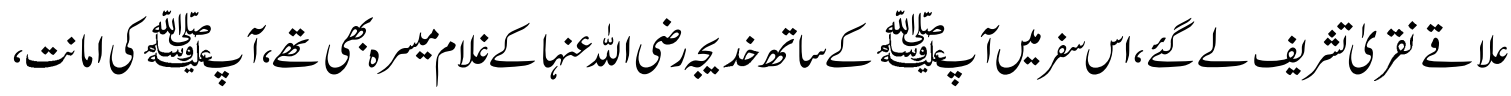

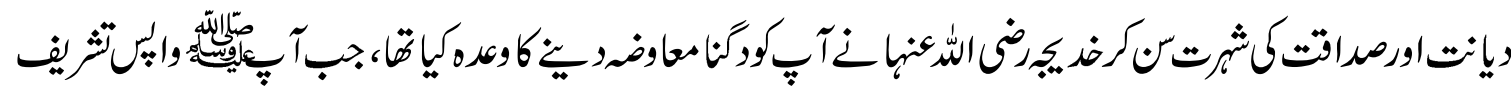

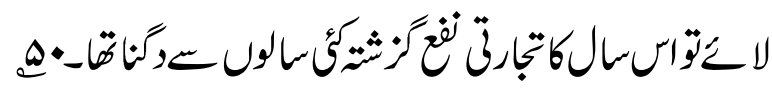




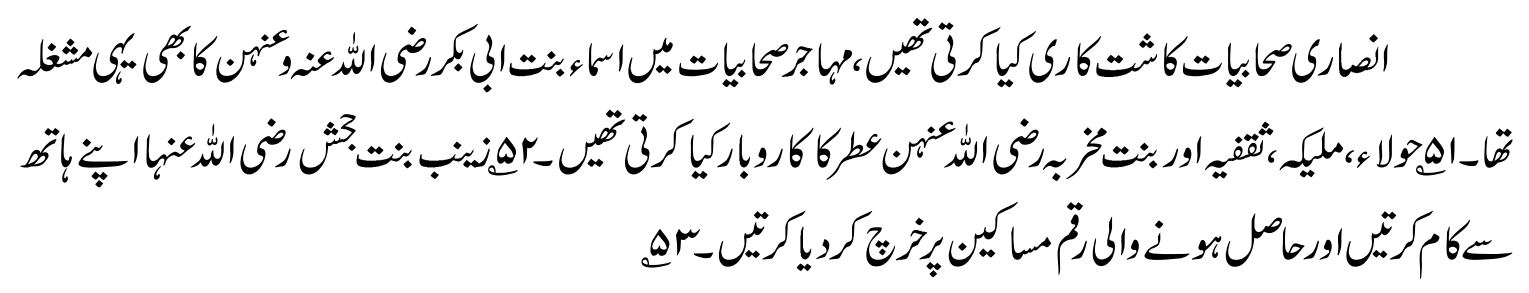

خلاص

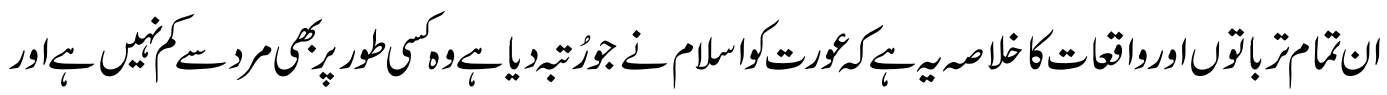

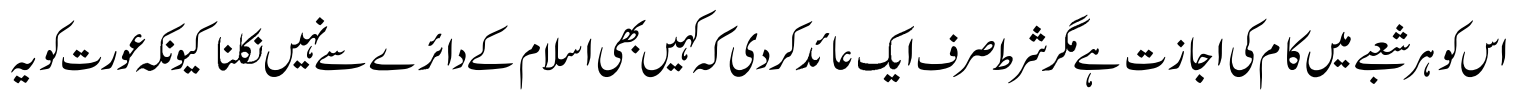

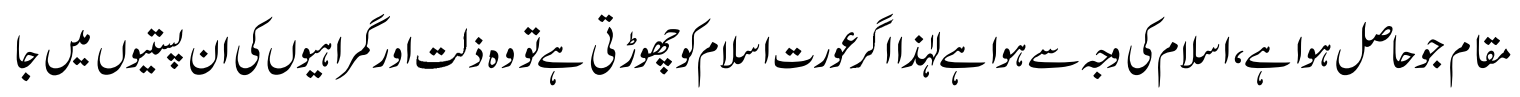

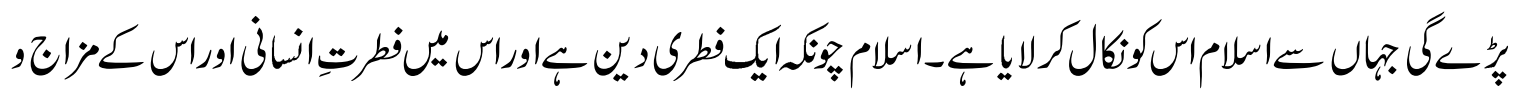

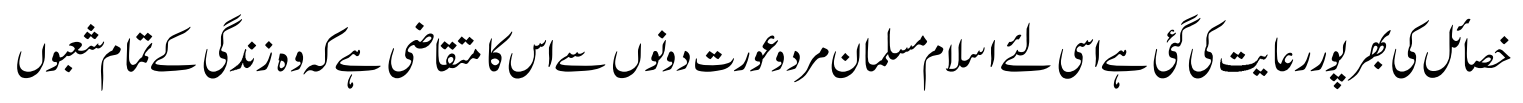

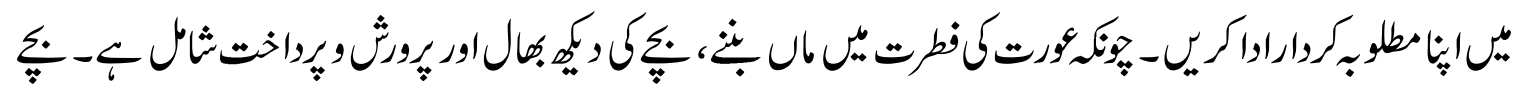

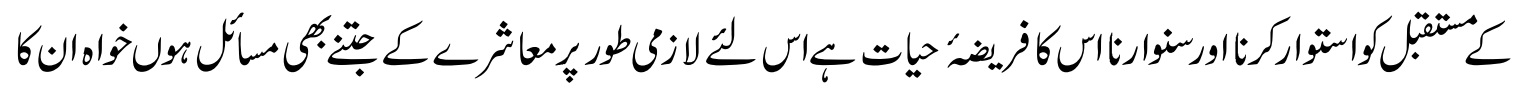

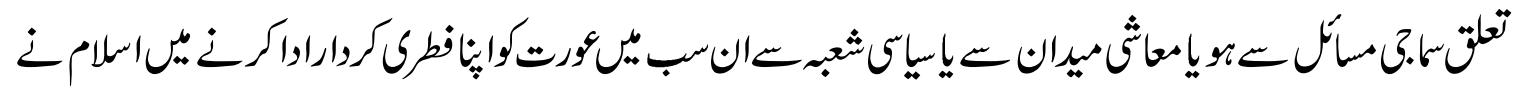

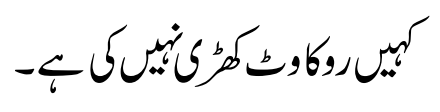

والرجات

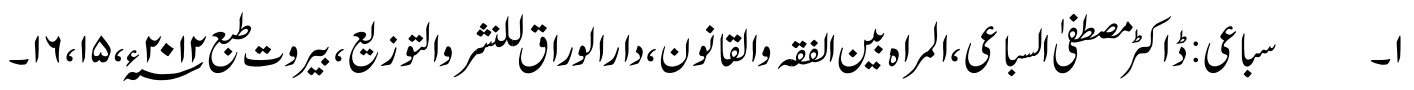

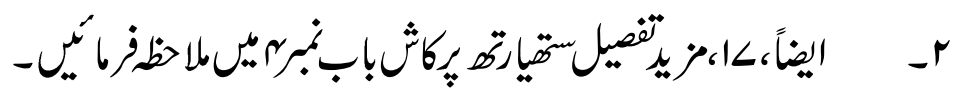
rrol

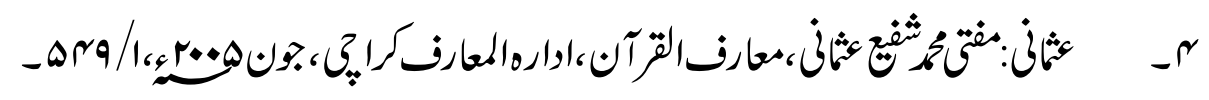

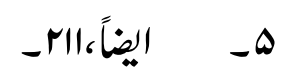




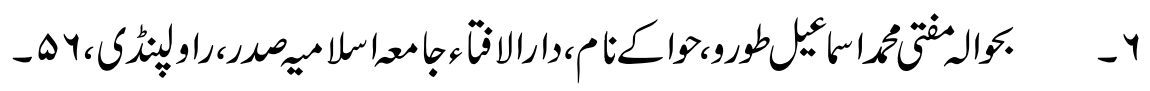

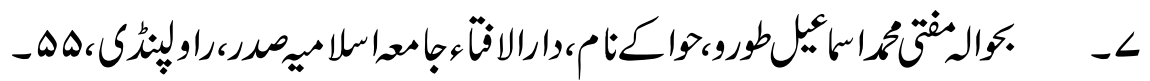

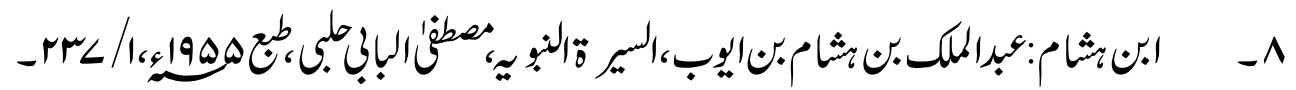

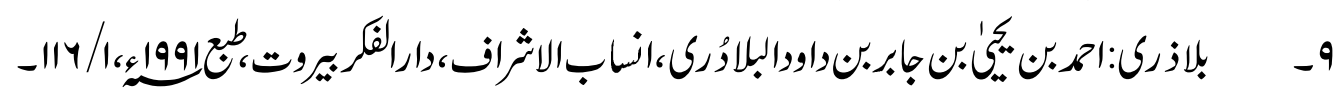

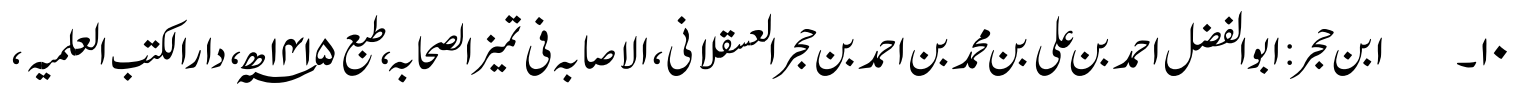
$-M / L / \Lambda$

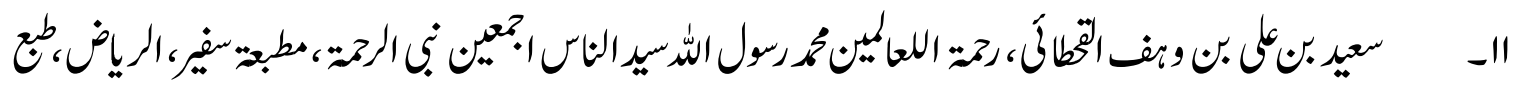

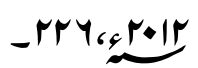

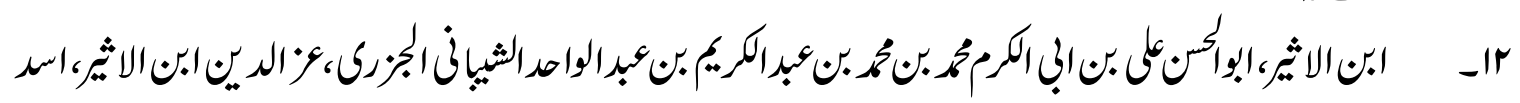

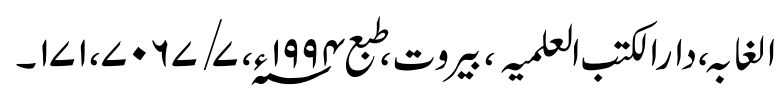

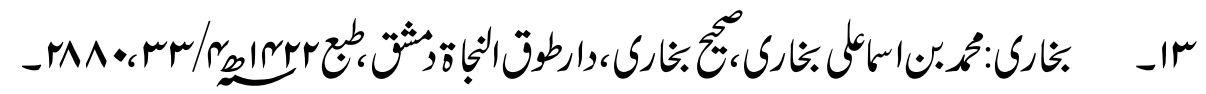

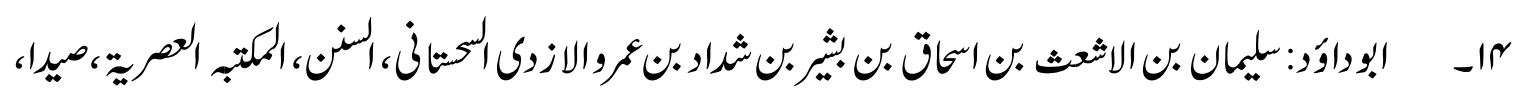
$-r r<r q<r / r$

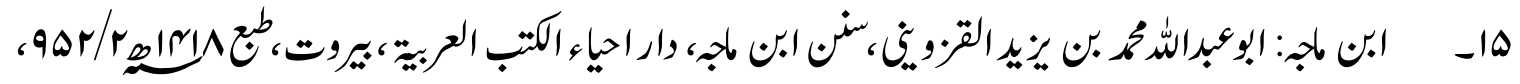
-MAQY

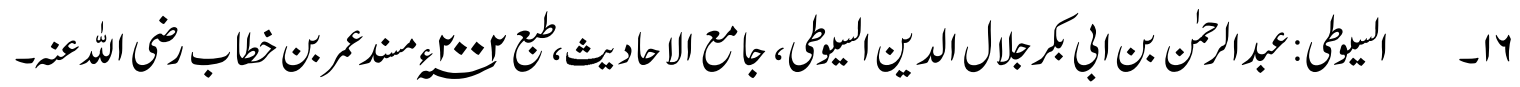
-ra../rar/ra

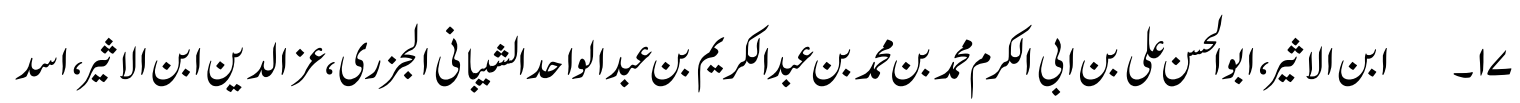

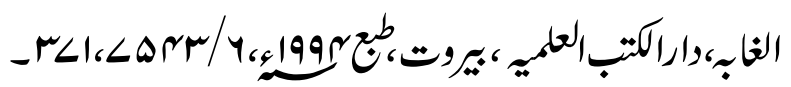

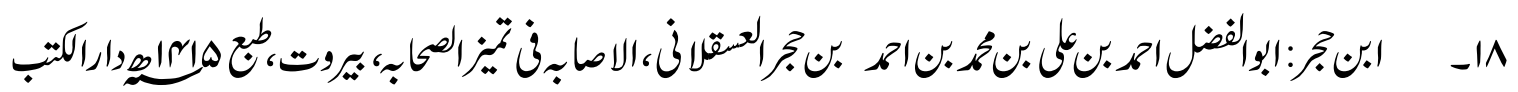

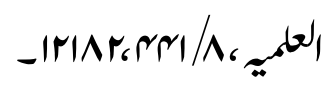




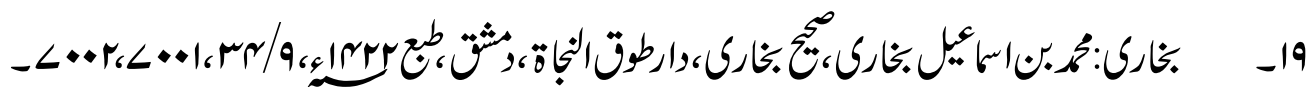

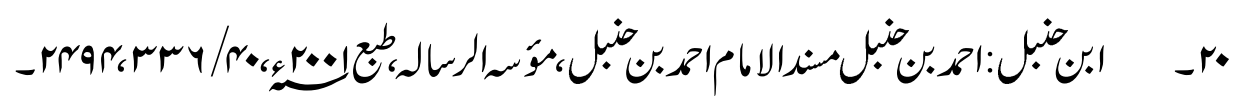

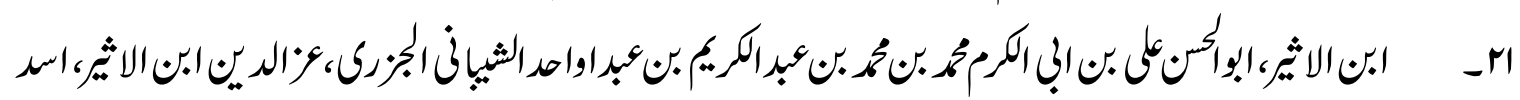

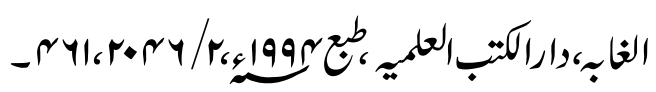

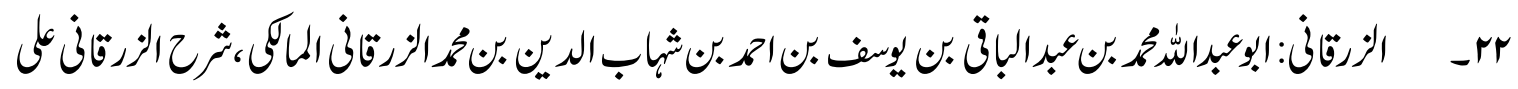

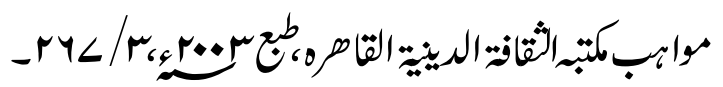

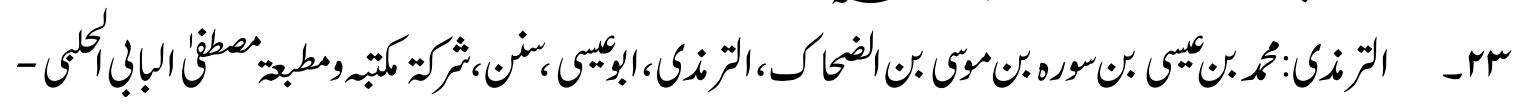

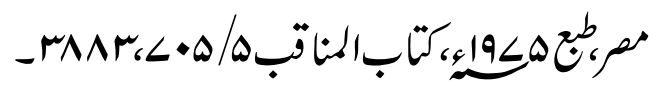

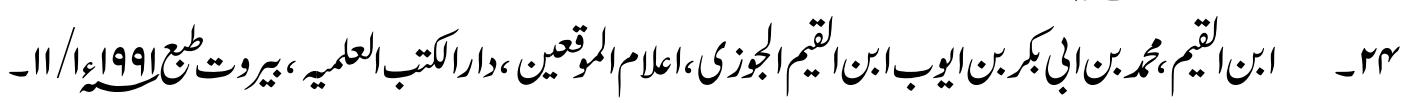

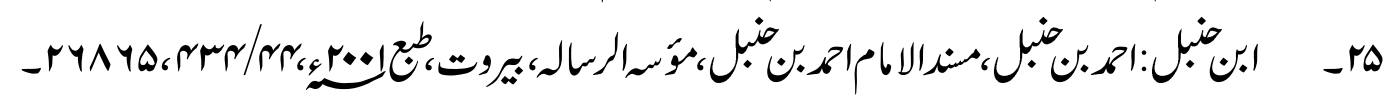

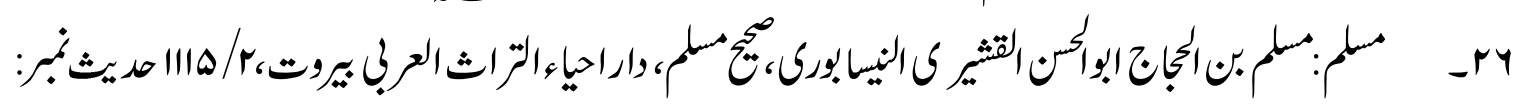
$-1 \% A$

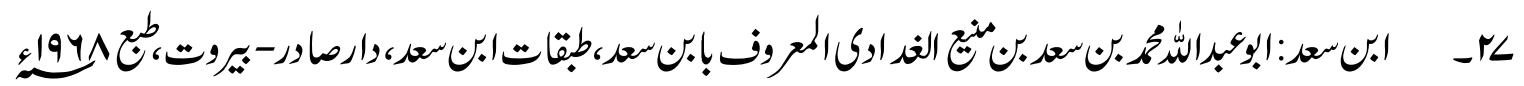

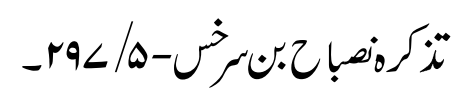

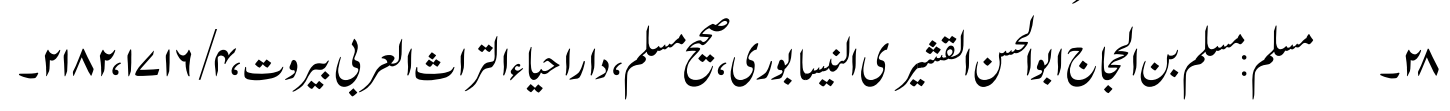

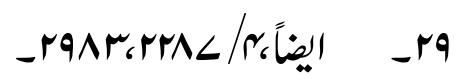

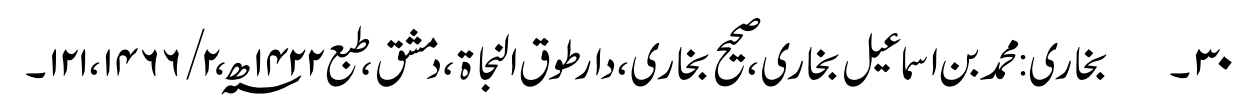

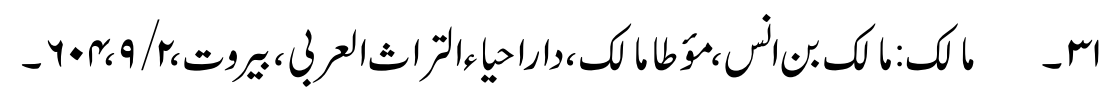
اليضاً

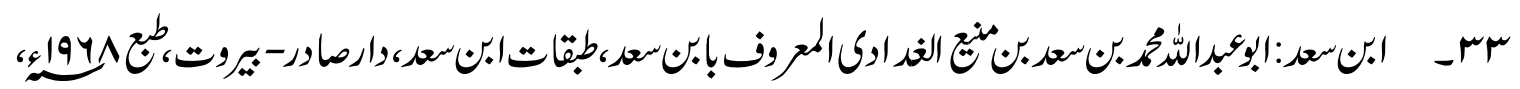
$-\Delta Y / \Lambda$ 


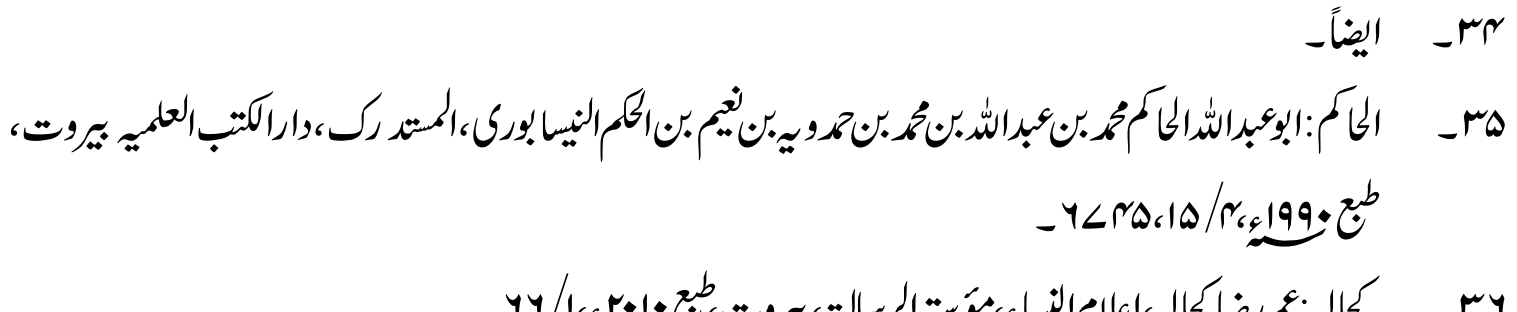

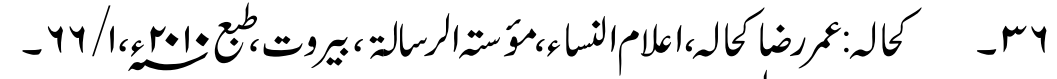

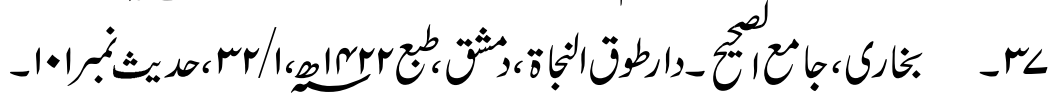

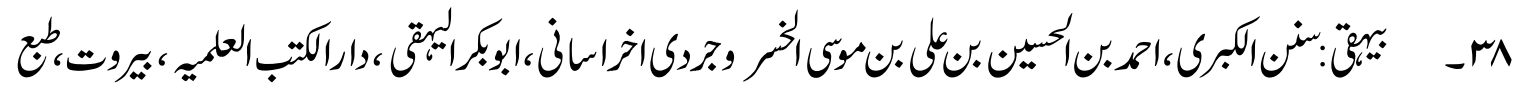

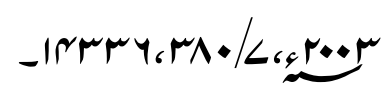

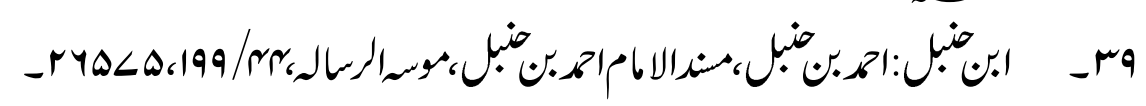

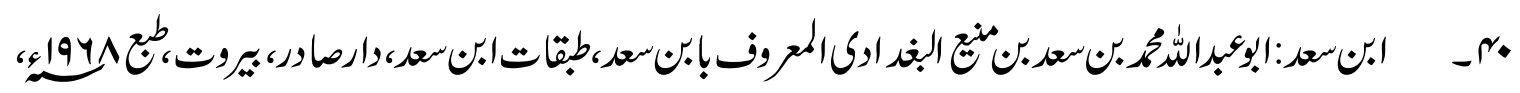
$-1 \Delta r / \Lambda$

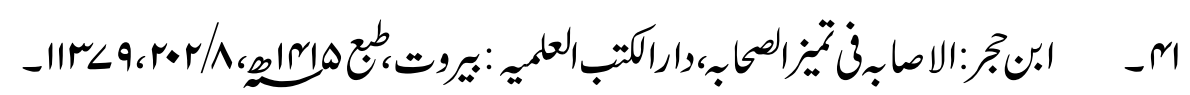
- اليضاً، إن

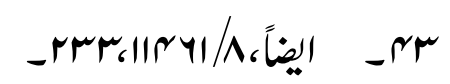

rer

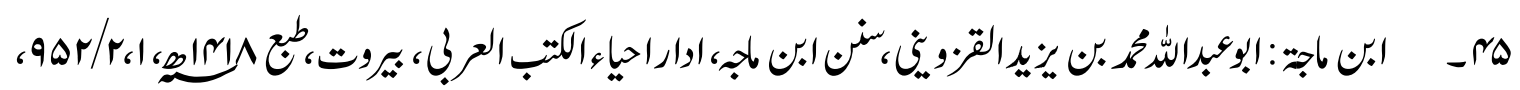
$-M \Delta Q Y$

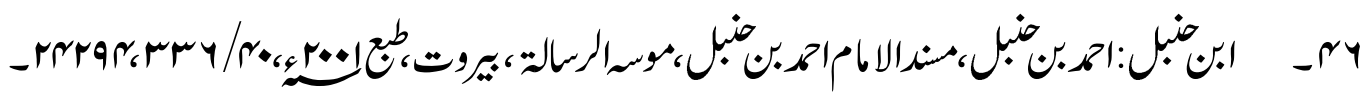

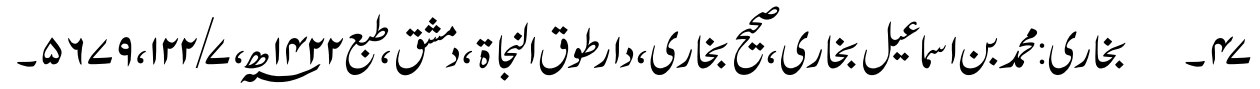

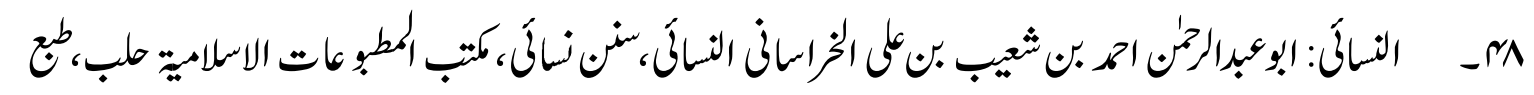
$-\Delta r_{6}<r \Lambda / r_{6 r g} / 9 \Lambda Y$

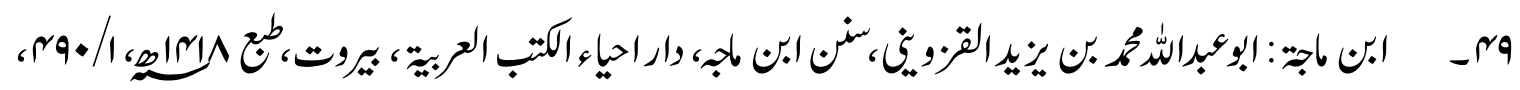


$-1 \Delta \mu \mu$

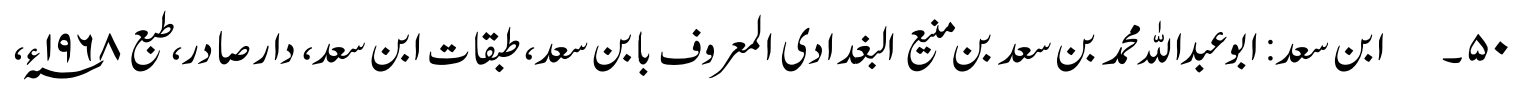
$-1 \pi \cdot / 1$

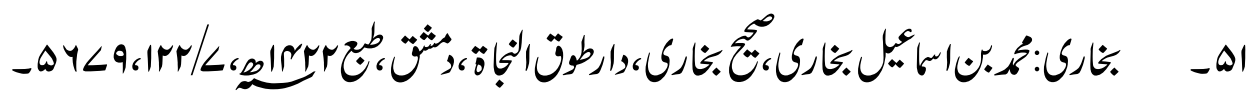

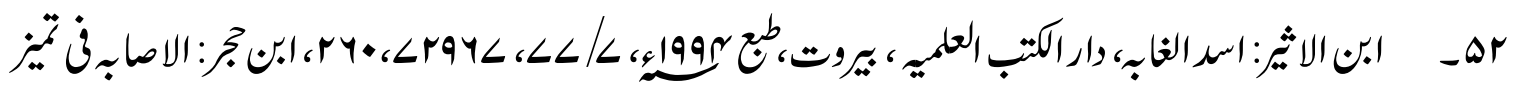

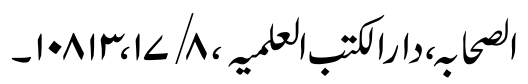

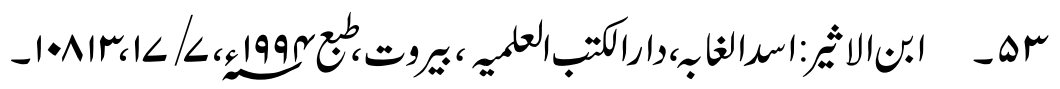

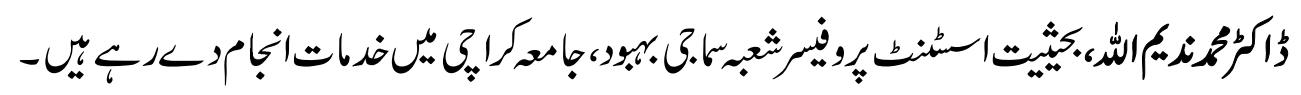

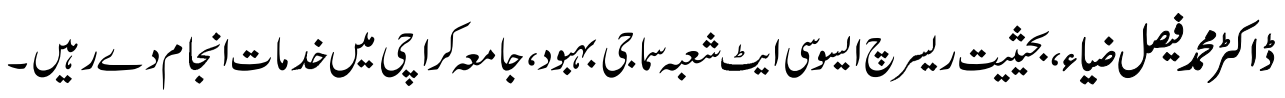

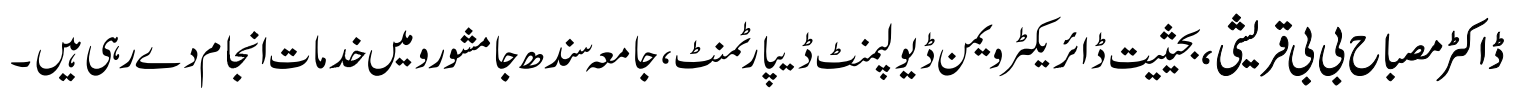

